\title{
The pore solution of blended cements: a review
}

\author{
Anya Vollpracht • Barbara Lothenbach • \\ Ruben Snellings · Johannes Haufe
}

Received: 27 April 2015/ Accepted: 28 September 2015/Published online: 15 October 2015

(C) RILEM 2015

\begin{abstract}
This paper is the work of working group 3 of the RILEM Technical Committee on Hydration and Microstructure of Concrete with SCM (TC 238-SCM). The pore solution is an essential but often overlooked part of hydrated cements. The composition of the cement pore solution reflects the ongoing hydration processes and determines which solid phases are stable and may precipitate, and which phases are unstable and may dissolve. The study of the cement pore solution therefore contributes to the understanding of the mechanisms as well as of the kinetics of cement hydration. This paper reviews the impact of supplementary cementitious materials (SCMs) on the pore solution composition of
\end{abstract}

Electronic supplementary material The online version of this article (doi:10.1617/s11527-015-0724-1) contains supplementary material, which is available to authorized users.

A. Vollpracht $(\bowtie) \cdot$ J. Haufe

Institute of Building Materials Research, RWTH Aachen University, Aachen, Germany

e-mail: vollpracht@ibac.rwth-aachen.de

\section{B. Lothenbach}

Laboratory Concrete \& Construction Chemistry, Empa, Dübendorf, Switzerland

\section{R. Snellings}

Institute of Materials, Ecole Polytechnique Fédérale de Lausanne (EPFL), Lausanne, Switzerland

\section{R. Snellings}

Sustainable Materials Management, Vlaamse Instelling voor Technologisch Onderzoek (VITO), Mol, Belgium blended cements. In a first part, the extraction and analysis methods of cement pore solutions are reviewed, leading to a set of practical guidelines and recommendations. In a second part, an extensive literature survey is used to document the effect of the addition of SCMs (blast furnace slag, fly ash and silica fume) on the pore solution. Finally, in a third part the collected literature data are compared to thermodynamic simulations. The performance and current limitations of thermodynamic modelling of blended cement hydration are demonstrated and discussed in view of future progress.

Keywords Pore solution · Supplementary cementitious materials $\cdot$ Blended cement $\cdot$ Analytical methods $\cdot$ Thermodynamic modelling

\section{Introduction}

This paper aims to contribute to the understanding of the reaction mechanisms and kinetics of supplementary cementitious materials (SCMs) in combination with Portland cement (PC) by reviewing their impact on the liquid phase of cement paste. The composition of the aqueous phase of hydrating cementitious materials gives important insights into the chemical processes and the interactions between solid and liquid phases. The composition of the liquid phase determines which hydrate phases are stable and can thus (potentially) precipitate and vice versa. The measured 
composition of the pore solution and its change in composition during hydration can be considered in many cases as a prerequisite for a complete thermodynamic model of hydrating cements.

Numerous authors have investigated the pore solution of cement pastes under different conditions. In this review, an extensive literature survey was carried out and information on chemical composition of the components, the mixture proportions of the pastes and the concentrations of hydroxide ions, sodium, potassium, calcium, sulfate, silicon and aluminium in the pore solution [1-42] were summarised in a database available as electronic supplementary source. Other authors have focussed on the concentrations of hydroxides and/or the sum of alkalis $(\mathrm{Na}+\mathrm{K})$ in the pore solution in the context of alkali silica reaction (e.g., [43-46]). As stated in [47] pore solution analysis is very useful for understanding deleterious reactions and durability. This paper is not dealing with durability but with the reaction mechanisms of SCMs. The publications mentioned above were not included in the database because the information on pore solution composition is limited to alkalinity.

In order to compare the general trends of the pore solution composition only the data measured between 20 and $23{ }^{\circ} \mathrm{C}$ are considered and the composition is restricted to pastes containing plain PCs and fly ash (FA), ground granulated blast furnace slag (GGBS) or silica fume (SF). No ternary blends are discussed and the water/binder ratio was limited to $w / b<1.0$.

The review first focuses on methods to obtain and determine the composition of pore solutions, and then discusses the changes in pore solution composition with time including the effect of different SCMs and the influence of the amount of SCM in the blend. To gain an understanding of the underlying mechanisms the effect of SCMs on the liquid composition and solid phase assemblage calculations were also performed using thermodynamic modelling.

The paper represents an output of the work of the RILEM Technical Committee on Hydration and Microstructure of Concrete with SCMs (TC-238SCM), working group 3 .

\section{Methods}

The extraction, analysis and modelling of cement pore solutions should be carried out with caution. Next to paying attention to occupational hazards related to operating high-pressure extraction devices or to manipulating corrosive solutions, due care has to be taken to ensure the preservation of the extracted solution during handling and storage before analysis. In addition, the different measurement principles or sample preparation procedures for the regular analytical techniques can lead to slightly different values for elemental or ionic solution concentrations. In the following section guidelines to the extraction, analysis and interpretation of cement pore solutions are given based upon a review of reported procedures.

\subsection{Extraction of pore solution}

During the first hours of hydration the liquid phase can be separated by vacuum filtration or centrifugation [48, 49]. After hardening, pore solution can either be obtained from pastes prepared with extremely high $w / c$ ratios [50-54] or by using a high pressure device to extract the pore solutions. Pore solution can also be obtained from mortars and concretes. Longuet et al. [18] were the first to describe such a high pressure device to extract pore solutions from hardened cement pastes.

As mentioned above only pore solutions of pastes with $w / b<1.0$ are considered in this paper. Therefore all the results at later ages are determined using high pressure devices. It has been argued that the expressed solution may not represent the real pore solution present in the hydrating cements (e.g., [55]). An increase of pressure could affect the composition of the solution. Some authors investigated the influence of pressure by applying different load stages on samples of the same composition and age. Duchesne and Bérubé investigated pore solutions from PC and PC blended with slag or FA prepared with a $w / c$ of 0.5 [57, 58]. Tritthart used a $w / c$ of 0.6 [59]. No significant influence of the pressure (up to 560 and $350 \mathrm{MPa}$, respectively) on the alkali, hydroxide and chloride concentrations was observed.

However pore solutions from PC samples with $w / c$ of 0.42 expelled at pressures up to $1000 \mathrm{MPa}$, showed an increase in alkali concentrations of $20-30 \%$ at higher pressures [60]. Table 1 summarises results from [56] for pore solutions gained at pressures between 60 and $330 \mathrm{MPa}(\mathrm{PC}, w / c=0.4)$. An increase in $\mathrm{Na}, \mathrm{K}$, and $\mathrm{OH}^{-}$concentration in the range of 4-9\% was found; a difference that is in the 
Table 1 Measured concentrations in the pore solutions of a PC $(w / c=0.4)$ hydrated for 69 days

\begin{tabular}{llllllllllll}
\hline $\begin{array}{l}\text { Pressure } \\
\mathrm{MPa}\end{array}$ & $\begin{array}{l}\mathrm{Li}^{\mathrm{a}} \\
\mathrm{mmol} / 1\end{array}$ & $\begin{array}{l}\mathrm{Na}^{\mathrm{a}} \\
\mathrm{mmol} / 1\end{array}$ & $\begin{array}{l}\mathrm{K}^{\mathrm{a}} \\
\mathrm{mmol} / 1\end{array}$ & $\begin{array}{l}\mathrm{Ca}^{\mathrm{a}} \\
\mathrm{mmol} / 1\end{array}$ & $\begin{array}{l}\mathrm{Sr}^{\mathrm{a}} \\
\mathrm{mmol} / 1\end{array}$ & $\begin{array}{l}\mathrm{Al}^{\mathrm{a}} \\
\mathrm{mmol} / 1\end{array}$ & $\begin{array}{l}\mathrm{Si}^{\mathrm{a}} \\
\mathrm{mmol} / 1\end{array}$ & $\begin{array}{l}\mathrm{S}^{\mathrm{a}} \\
\mathrm{mmol} / 1\end{array}$ & $\begin{array}{l}\mathrm{OH}^{-\mathrm{b}} \\
\mathrm{mmol} / 1\end{array}$ & $\begin{array}{l}\mathrm{pH}^{\mathrm{C}} \\
-\end{array}$ \\
\hline $60-120$ & 0.69 & 46 & 450 & 1.8 & 0.046 & 0.09 & 0.21 & 8.2 & 490 & 13.6 & 0 \\
$120-150$ & 0.69 & 49 & 480 & 2.0 & 0.050 & 0.09 & 0.21 & 9.2 & 490 & 13.6 & 5 \\
$150-180$ & 0.69 & 49 & 480 & 2.0 & 0.050 & 0.09 & 0.23 & 10 & 490 & 13.6 & 5 \\
$180-270$ & 0.69 & 50 & 490 & 2.0 & 0.050 & 0.09 & 0.24 & 12 & 490 & 13.6 & 7 \\
$270-330$ & 0.63 & 50 & 480 & 1.9 & 0.050 & 0.09 & 0.26 & 13 & 500 & 13.6 & 1 \\
\hline
\end{tabular}

Reproduced from [56]

a Total concentrations determined with ICP-OES (inductively coupled plasma optical emission spectroscopy)

b The values for $\mathrm{OH}^{-}$refer to free concentrations that were calculated from $\mathrm{pH}$

c The charge balance error $\mathrm{CB}$ gives the surplus of cations (cations-anions), relative to the total charge caused theoretically by cations (i.e., $\left[\mathrm{Na}^{+}\right]+\left[\mathrm{K}^{+}\right]+2\left[\mathrm{Ca}^{2+}\right]$ )

range of the variability of pore solution extraction data [59]. Also for silicon only a slight increase of the concentrations with pressure is observed. For sulfate, however, a clear increase of the measured concentrations with increasing pressure is found.

These data indicate that the concentrations expelled with pressures up to approx. $250 \mathrm{MPa}$ are comparable to each other, even though sulfate concentrations increase slightly with the pressure applied. At higher pressures ( $>250 \mathrm{MPa}$ ), however, the composition may differ significantly. The high pressures applied to expel the pore solutions could be the cause of this concentration increase, as high pressures could increase the solubility of solids. For the collection of an adequate amount of pore solution for the analysis from cement pastes a pressure of $250 \mathrm{MPa}$ is usually sufficient. Higher pressures may be necessary for mortar or concrete.

\subsection{Methods for chemical analysis}

Experimental details on how the pore solutions are handled after extraction are often not provided in the references. However, the first step is often a dilution to avoid the precipitation of solids within the solution before the measurements. Depending on the analytical method, the dilution should be at least 1:10. For analysis with inductively coupled plasma optical emission spectroscopy (ICP-OES) the diluted samples have to be acidified immediately to a $\mathrm{pH}$ of about 1 . The analysis should be completed within 14 days. For ion chromatography (IC) analysis the samples are not acidified but only diluted. To avoid precipitation the solutions should be analysed within a few days. Prior to analysis the pore solution should be stored at $5 \pm 2{ }^{\circ} \mathrm{C}$. Table 2 summarises the methods described in literature. Recommendations and comments are given in the last column. It is recommended to analyse at least the main ions $\left(\mathrm{OH}^{-}, \mathrm{Na}, \mathrm{K}, \mathrm{Ca}\right.$, sulfur $)$ and to check the ionic balance. Very high discrepancies $(>20 \%)$ between anions and cations indicate the presence of high concentrations of other ions or analytical problems. Pore solution samples with high imbalance were excluded from the database.

Some authors calculate the $\mathrm{pH}$-value from the hydroxide concentrations or vice versa (e.g., [3, 21]). Figure 1 shows the $\mathrm{pH}$-value calculated according to Eq. 1 from hydroxide concentrations obtained by titrations plotted against the directly measured $\mathrm{pH}$ value for different binder compositions. The $\mathrm{pH}$ values calculated from the titrations tend to overestimate the measured $\mathrm{pH}$-values, as titration results include also hydroxides present as dissolved complexes such as $\mathrm{KOH}^{0}$ or $\mathrm{CaOH}^{+}$.

$\mathrm{pH}_{\mathrm{cal}}=\log \left(c_{\mathrm{OH}^{-}}\right)+14.0$,

$c_{\mathrm{OH}^{-}}$is the hydroxide concentration in mol/l (determined via titration), $\log K_{\mathrm{w}} \approx 14.18$ at $20{ }^{\circ} \mathrm{C}$ and $\approx 14.0$ at $25{ }^{\circ} \mathrm{C}$.

\subsection{Thermodynamic modelling}

Thermodynamic modelling is used to calculate the effect of the quantity of SCMs on the pore solution composition and the hydrate assemblage; the results are compared with experimental data from the literature. The chemical composition of the PC, FA and SF used in the calculations is compiled in the Chap. 4, 
Table 2 Analytical methods for the analysis of pore solution

\begin{tabular}{|c|c|c|}
\hline Substance/parameters & Methods & Recommendations/comments \\
\hline $\mathrm{pH}$-value & Electrode & $\begin{array}{l}\text { Measurements have to be carried out on the undiluted sample preferably the same } \\
\text { day as the high } \mathrm{pH} \text { solutions can carbonate even in closed plastic vessels, which } \\
\text { will lower the } \mathrm{pH} \text { significantly. Solution } \mathrm{pH} \text { should be measured on a separate } \\
\text { sample to avoid } \mathrm{K} \text { and } \mathrm{Cl} \text { contamination by the reference electrode. Since } \\
\text { commercial buffer solutions are available up to } \mathrm{pH} 12 \text { (or 13) only, it is } \\
\text { recommended to use freshly prepared alkali-hydroxide solutions (generally } \\
\mathrm{KOH} \text { ) as reference solutions [18]. The preparation of hydroxide standard } \\
\text { solutions offers in addition the possibility to mix in the appropriate } \\
\text { concentration of } \mathrm{NaOH} \text { or LiOH and to account in that way for the alkali error } \\
\text { [61]. } \\
\text { (The presence of } \mathrm{Li}^{+} \text {and to a lesser extent also of } \mathrm{Na}^{+} \text {can lead to an } \\
\text { overestimation of the } \mathrm{H}^{+} \text {concentration and thus to too low pH values). }\end{array}$ \\
\hline \multirow[t]{2}{*}{$\mathrm{OH}^{-}$} & Titration & $\begin{array}{l}\text { Titration will result in somewhat higher hydroxide concentrations, as not only } \\
\text { "free" hydroxide is measured, but also hydroxides present in dissolved } \\
\text { complexes such as } \mathrm{CaOH}^{+} \text {are included. }\end{array}$ \\
\hline & $\begin{array}{l}\text { Indicators: } \\
\text { phenolphthalein, } \\
\text { methyl red }\end{array}$ & $\begin{array}{l}\text { Titration against phenolphthalein }(\mathrm{pH} 8.2) \text { leaves carbonate ions }\left(\mathrm{CO}_{3}^{2-}\right) \\
\text { unaltered, whereas titration against methyl red }(\mathrm{pH} 4.3) \text { leads to formation of } \\
\mathrm{HCO}_{3}^{-} \text {. By combining both values, the } \mathrm{CO}_{3}^{2-} \text { concentration in the original pore } \\
\text { solution can be calculated. }\end{array}$ \\
\hline
\end{tabular}

\begin{tabular}{|c|c|c|}
\hline $\mathrm{Na}, \mathrm{K}, \mathrm{Ca}$ & $\begin{array}{l}\text { Flame photometry } \\
\text { AAS } \\
\text { IC }\end{array}$ & $\begin{array}{l}\text { All methods are recommendable and measure the total concentration of the } \\
\text { respective element. Calcium precipitates very easily, if the samples are not } \\
\text { acidified (e.g., for flame photometry or IC). }\end{array}$ \\
\hline
\end{tabular}

ICP-OES

$\begin{array}{ll}\text { S } & \text { IC (as sulfate) } \\ & \text { ICP-OES (total sulfur) } \\ & \text { AAS }\end{array}$

IC and ICP-OES are the most common methods. Generally the sulfate concentrations determined by IC agree with the total sulfur concentrations from ICP-OES [17], with the notable exception of cements containing slags, where reduced sulfur species such as $\mathrm{HS}^{-}$are present. For slag containing cements the Precipitation as $\mathrm{BaSO}_{4}$ pore solutions should not be acidified to avoid the evaporation of gaseous $\mathrm{H}_{2} \mathrm{~S}$ and $\mathrm{SO}_{2}$. Details on the analysis of pore solution containing reduced sulfur species are given in [21].

An alternative could be the precipitation of sulfates with $\mathrm{BaCl}_{2}$. However the method seems to lead to overestimation of the dissolved sulfate concentration [24] and is not recommended. These values were excluded from the database.

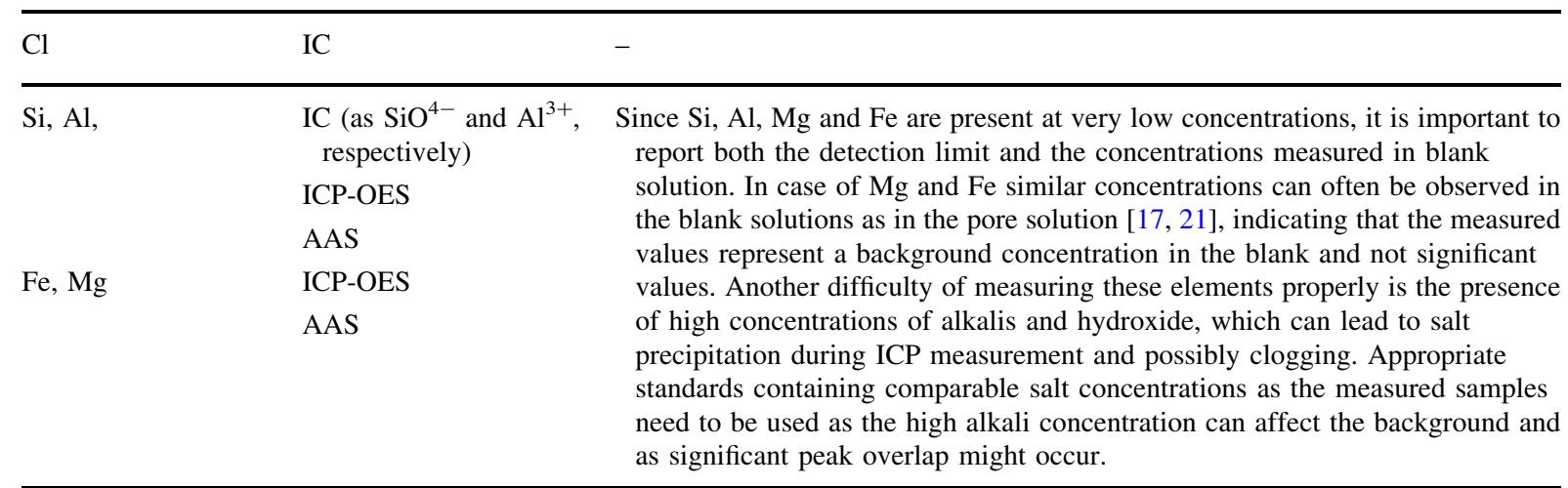

$\overline{A A S \text { atomic absorption spectrometry, IC ion chromatography, ICP-OES inductively coupled plasma optical emission spectrometry }}$ 


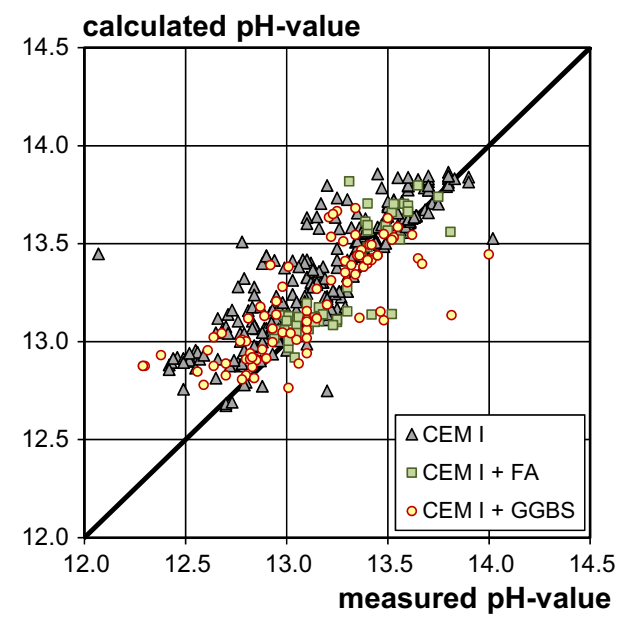

Fig. 1 Comparison of calculated and measured $\mathrm{pH}$-value of pore solutions with different binder compositions

Tables 3 and 4. Thermodynamic equilibrium calculations predict the composition of a system composed of aqueous, solid and gaseous phases at the temperature and pressure of interest. Thermodynamic calculations, however, are more than just an easy tool for calculations. They allow testing different concepts and prevent us from making assumptions that violate mass conservation. The comparison with experimental data enables us to validate the calculations as well as the underlying assumptions.

Thermodynamic modelling was carried out using the Gibbs free energy minimization program GEMS $[62,63]$. GEMS is a geochemical modelling code which computes equilibrium speciation of the dissolved species as well as the kind and amount of solids precipitated. Chemical interactions involving solids, solid solutions, aqueous electrolyte and gas phase are considered simultaneously. The thermodynamic data for aqueous species as well as for many solids were taken from the PSI-GEMS thermodynamic database $[64,65]$, while the solubility products for cement minerals were taken from the cemdata07 database [66, 67] completed with the recently determined solubility products of siliceous hydrogarnet [68] and the CSHQ model for C-S-H [59]. The CSHQ model as given in Kulik [69] calculates, based on an ideal solid solution between different end-members, compositions of the solid $\mathrm{C}-\mathrm{S}-\mathrm{H}$ from a $\mathrm{Ca} / \mathrm{Si}=0.67$ to approximately $\mathrm{Ca} / \mathrm{Si}=1.6$. Iron was assumed to precipitate in all cases as ferrihydrite. The formation of the siliceous hydrogarnet and thaumasite was excluded due to kinetic reasons $[68,70]$. To model the uptake of alkali by $\mathrm{C}-\mathrm{S}-\mathrm{H}$ an ideal solid solution model between $\mathrm{C}-\mathrm{S}-$ $\mathrm{H}$ and two hypothetical alkali silicate hydrates $\left(\left[(\mathrm{KOH})_{2.5} \mathrm{SiO}_{2} \mathrm{H}_{2} \mathrm{O}\right]_{0.2}\right.$ and $\left.\left[(\mathrm{NaOH})_{2.5} \mathrm{SiO}_{2} \mathrm{H}_{2} \mathrm{O}\right]_{0.2}\right)$ [24] were used as proposed by Kulik et al. [71].

Thermodynamic modelling was carried out in a manner similar to that developed previously for PC and blended cements [21, 24, 25]. The kind and amount of hydrates formed during the hydration of the PCs and the blended cements were calculated by assuming complete reaction of the PC and a limited reaction of the SCM, as the SCM react more slowly than PC [72]. The degree of reaction (DoR) of FA and SF has been estimated based on literature data. The DoR of the FA has been evaluated by using data from different class F FAs [10, 39, 73 and 74] (see Fig. 2). Although different class F FAs have been used in these studies, they show comparable reactivity. The DoR of the FA decreased with increasing replacement ratio. Therefore, a linear function has been used to describe the DoR at ages of 28 days as well as 12 years. SF showed generally a higher DoR and a DoR of $60 \%$ was used for 28 days and of $80 \%$ after 1 year [25, 75-77].

\section{Cement pore solutions over time}

The cement pore solution composition varies over time. In this section the impact of SCMs on the cement pore solution behaviour over time is documented by an extensive literature review. First the trends in ionic concentrations in plain PC pore solutions are described statistically. Next, the established trends are compared to reported pore solution compositions of cements blended with GGBS, FA and SF and the impact of the SCMs is interpreted and discussed. The discussion is limited to cement pastes of $w / b$ ratios of $0.4-0.5$ for alkali and hydroxide concentrations and to cement pastes of $w /$ $b$ ratios $<1$ for total $\mathrm{Ca}, \mathrm{S}, \mathrm{Al}$ and $\mathrm{Si}$ concentrations.

\subsection{Portland cement}

\subsubsection{Statistical evaluation}

To compare the composition of pore solutions of pastes with SCM with pure PC pastes, the typical behaviour of the pore solution of CEM I pastes is discussed. For each element or ion the data at 


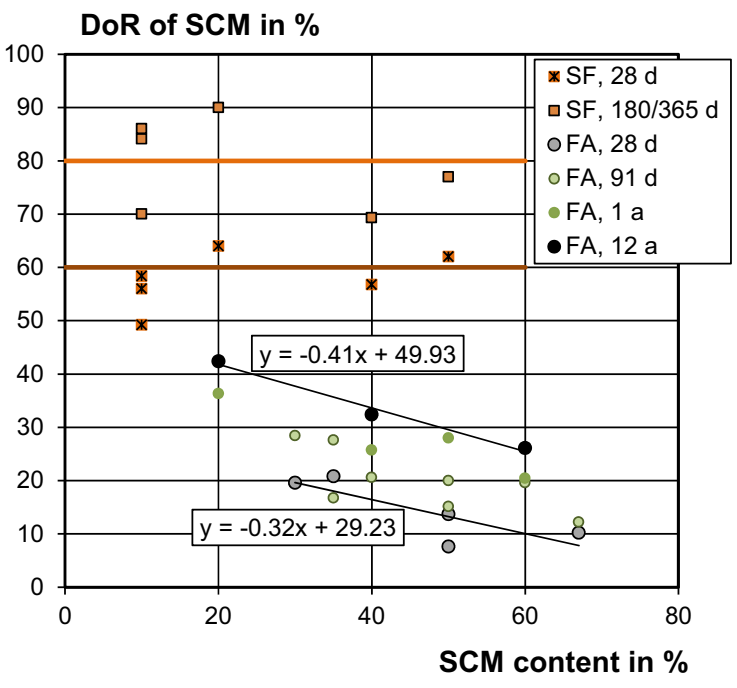

Fig. 2 Collected data on the dependence of the degree of reaction of silica fume $[25,75-77]$ and fly ash $[10,39,73,74]$ on the cement replacement ratio for selected ages

approximately the same hydration time were grouped together and their statistical distribution function analysed. Most of the datasets fit to a log-normal distribution. The mean value and the 2.5 and 97.5 percentiles were calculated for each set of data according to this statistical distribution. The values for the different time plots were fitted with several polynomial functions to get a curve for the mean concentration and a range with $95 \%$ of all measured concentrations. The procedure is illustrated in Fig. 3.

\subsubsection{Alkali and hydroxide concentrations}

Alkali sulfate phases contained in the cement dissolve within the first minutes when water is added. Due to the consumption of water during the hydration process and also a release of alkalis incorporated into clinker phases the alkali concentration increases over time, although a part of the alkalis is bound in $\mathrm{C}-\mathrm{S}-\mathrm{H}[21$, 78]. After 10 days only minor changes are observed.

An overview of all data is provided in Figs. 4 and 5. The data for $w / c$ ratios of $0.4-0.5$ is used in Fig. 6 to show and discuss common trends.

The concentrations of potassium and sodium depend on the $w / c$ ratio of the pastes and the total content of $\mathrm{K}_{2} \mathrm{O}$ and $\mathrm{Na}_{2} \mathrm{O}$ of the PC. For $w / c$ ratios of 0.6 and above lower potassium concentrations are observed due to dilution.

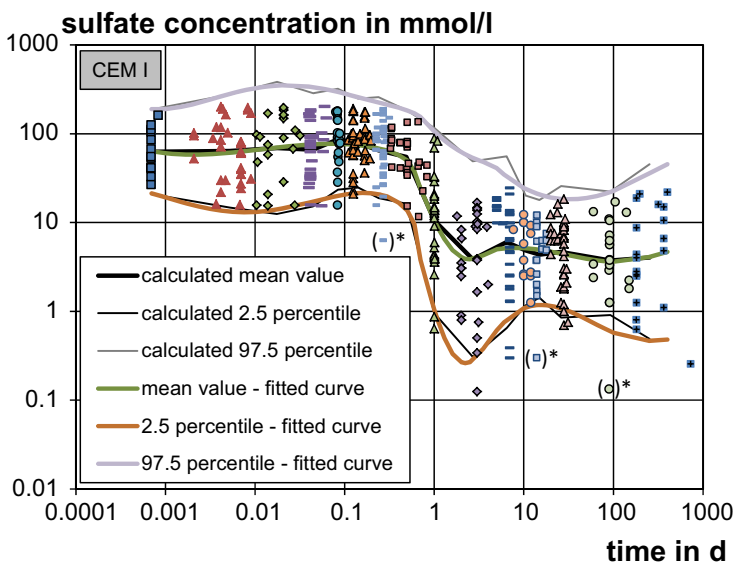

Fig. 3 Statistical evaluation of the data of pore solutions from CEM I pastes (example: sulfate) (*outliers)

For the statistical evaluation only the results for $w / c$ ratios of $0.4-0.5$ and potassium contents of the cement in the range of $0.76-1.03 \mathrm{wt} \%$ were considered, since both of the average compositions used for the thermodynamic modelling are within these limits. For sodium the selected content is $0.20-0.31 \mathrm{wt} \%$. The results are shown in Fig. 6.

The concentrations of $\mathrm{OH}^{-}$in the pore solution depend on the alkali concentrations and thus on the $w / c$ ratio (compare Figs. 4, 5), higher $w / c$ ratio dilute the alkali concentrations. The higher the alkali (and the lower the sulfate) concentration, the higher the hydroxide concentration, as the pore solutions are charge balanced. At later ages ( $>1$ day) sulfate concentrations are low and thus alkali concentrations are the main factor responsible for the hydroxide concentration. Figure 7 thus shows a more distinct increase of the hydroxide concentrations with time than observed for potassium or sodium.

\subsubsection{Calcium and sulfate concentrations}

The concentrations of calcium and sulfate depend on the solubility of the phases present at the particular stage of hydration. Therefore they depend little on the $w / c$ ratio (see Fig. 8), although the $\mathrm{pH}$ values influence the calcium concentrations. During the first hours the concentrations are limited by the presence of gypsum $\left(\mathrm{CaSO}_{4} \cdot 2 \mathrm{H}_{2} \mathrm{O}\right)$ or anhydrite $\left(\mathrm{CaSO}_{4}\right)$, and portlandite $\left(\mathrm{Ca}(\mathrm{OH})_{2}\right)$. A significant change is observed during the acceleration period between $6 \mathrm{~h}$ and 1 day; calcium and sulfate concentrations decrease as solid 

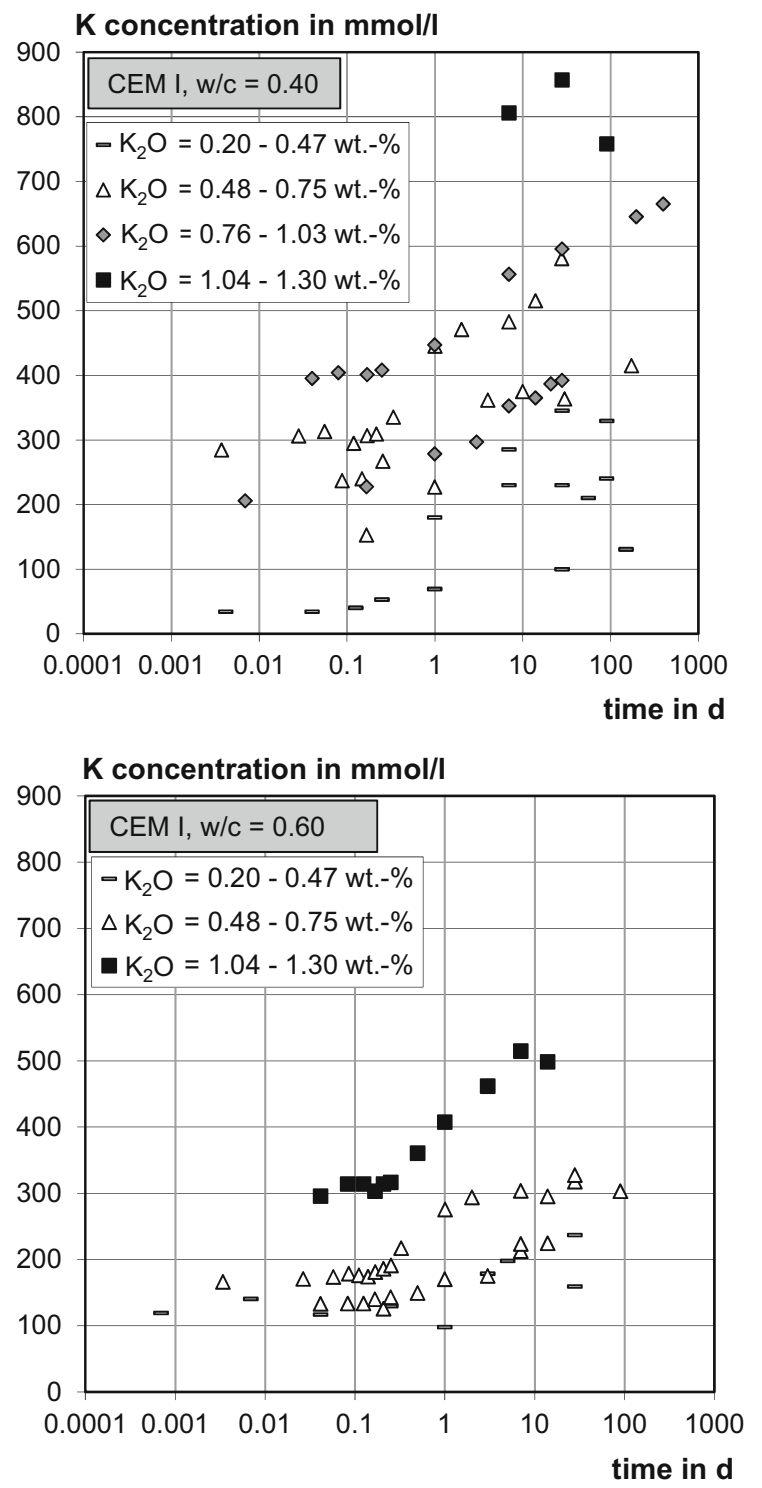
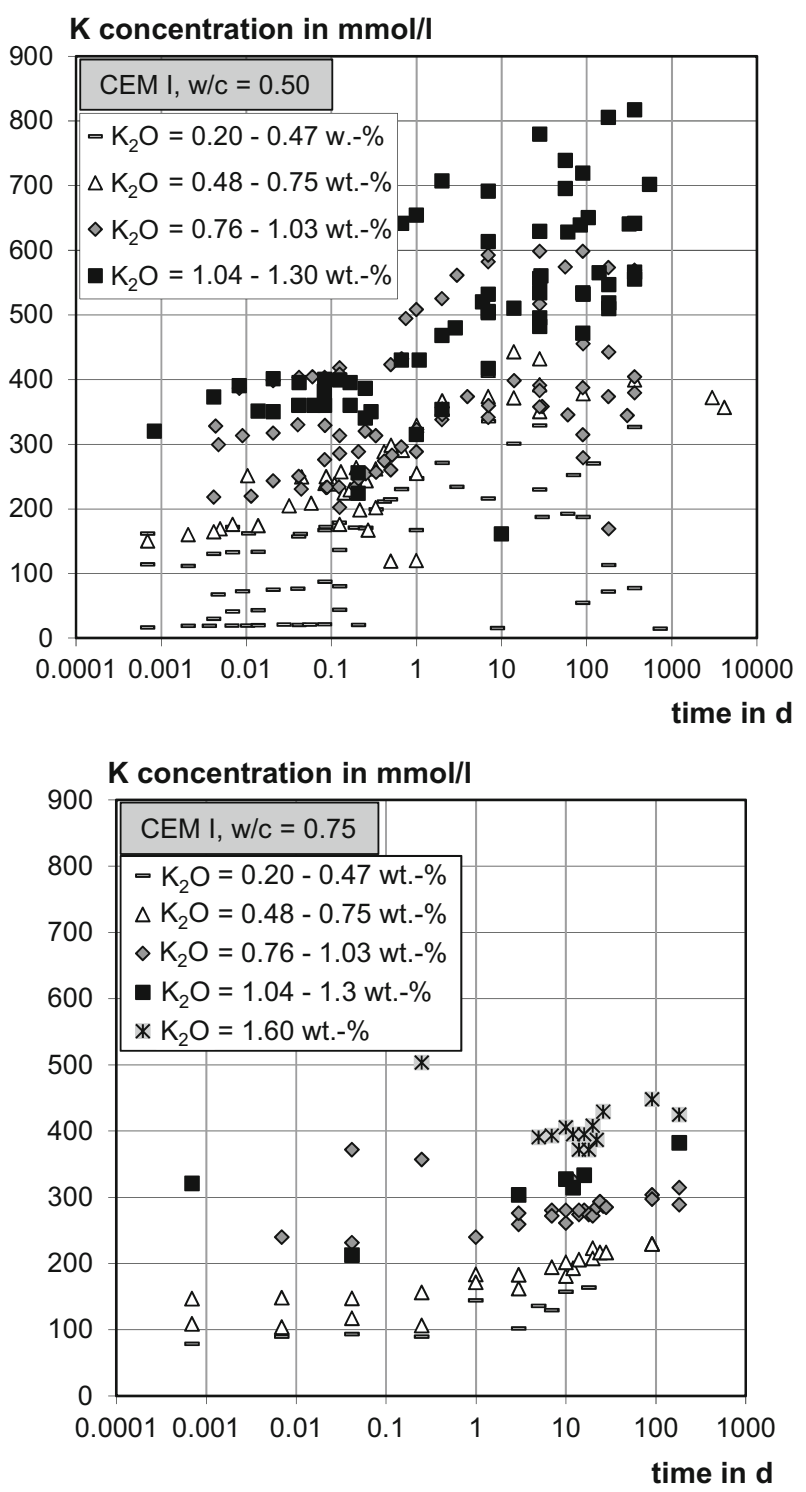

Fig. 4 Experimental data on pore solution concentrations of potassium of pure PC pastes [1-42]

gypsum and anhydrite are depleted due to the formation of ettringite.

The calcium concentration is determined by the solubility of portlandite and thus decreases with increasing $\mathrm{pH}$ or $\mathrm{OH}^{-}$concentration through the common ion effect. The same trend was found in [79]. The data follow in general the trend indicated by the portlandite solubility (see Fig. 9). However, many of the measured concentrations are above the calculated portlandite solubility and a significant scatter is observed. The scatter is probably related to the different measurement methods to determine hydroxide, sulfate and calcium concentrations. In the presence of high sulfate concentrations higher calcium concentrations are expected due to the formation of aqueous $\mathrm{CaSO}_{4}^{0}$ complexes. As observed previously, the pore solutions tend to be oversaturated with respect to portlandite especially at early ages.

Some authors state that higher $\mathrm{pH}$-values give rise to higher sulfate concentrations $[20,21,23,30,54,80$ 82]. Figure 10 shows the sulfate concentrations as a function of the $\mathrm{OH}^{-}$concentration. Two groups of data can be distinguished. During the first hours the sulfate concentrations follow the gypsum solubility 


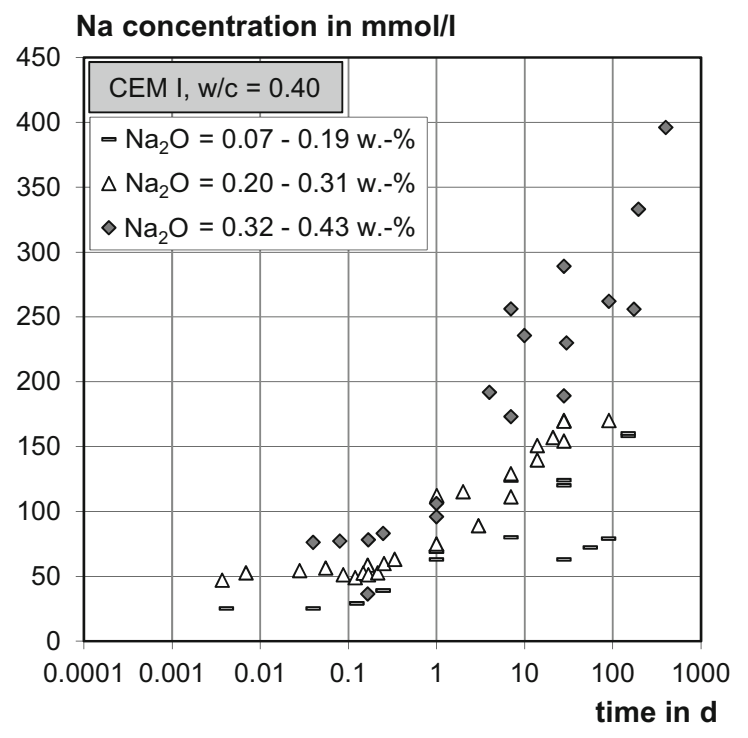

Na concentration in $\mathrm{mmol} / \mathrm{l}$

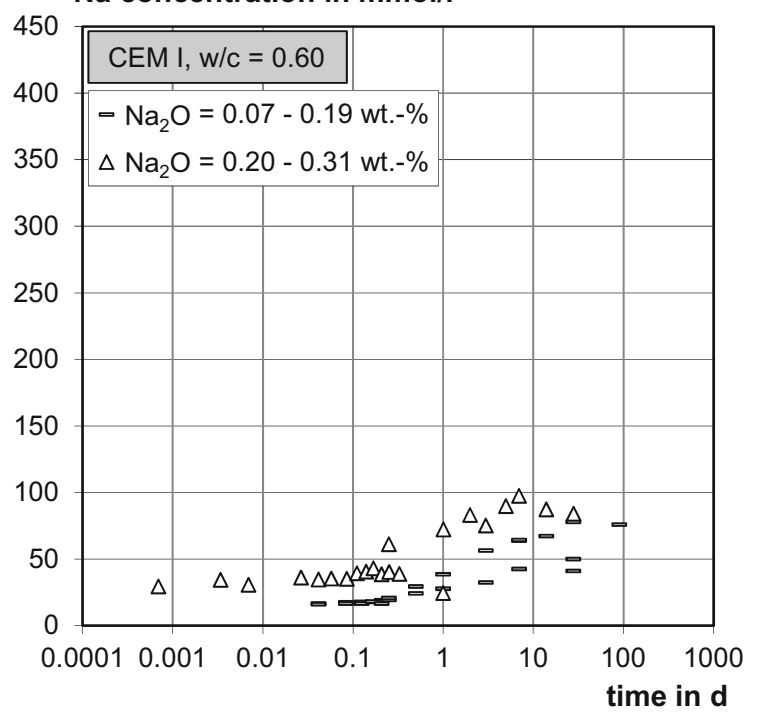

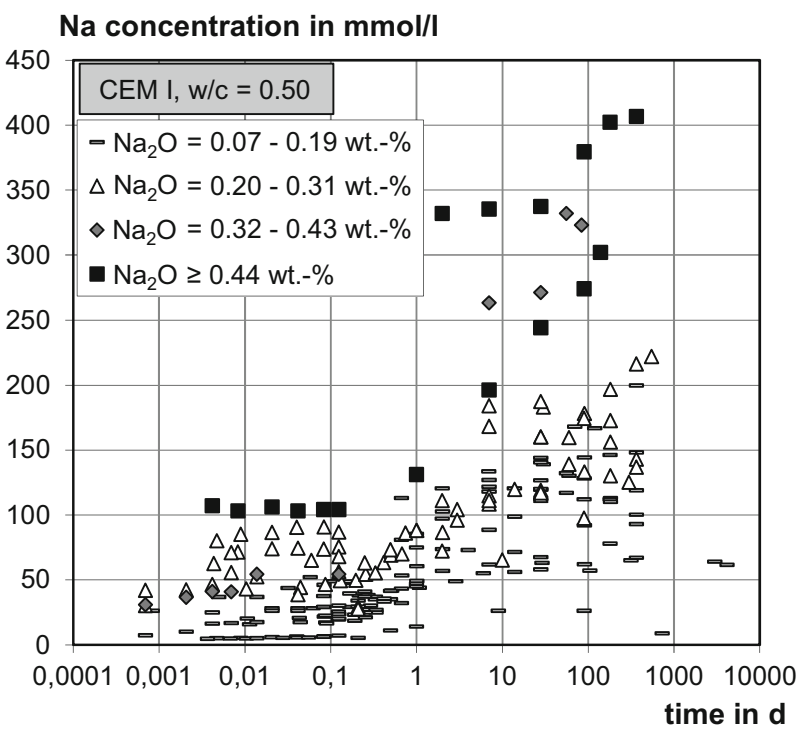

$\mathrm{Na}$ concentration in $\mathrm{mmol} / \mathrm{l}$

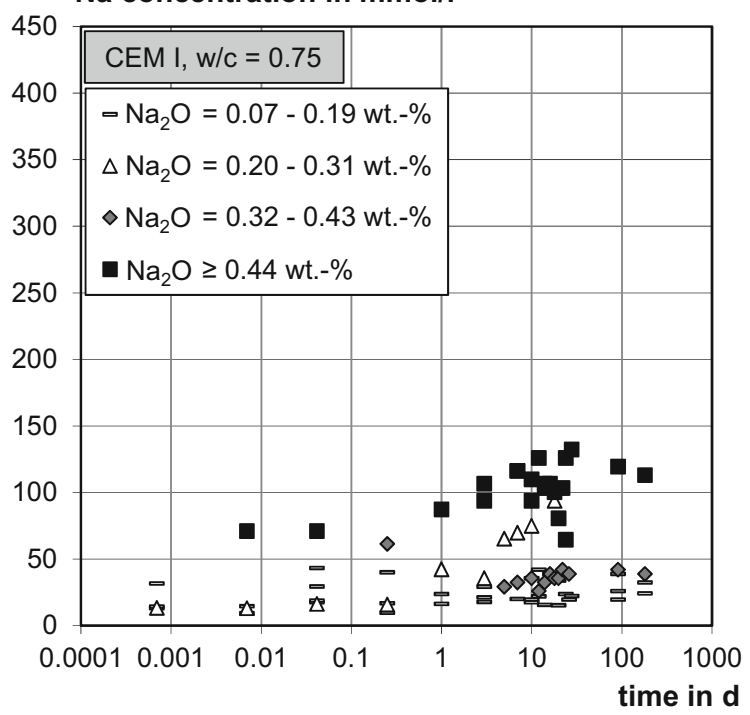

Fig. 5 Experimental data on pore solution concentrations of sodium of pure PC pastes [1-42]

and show a tendency to increase with $\mathrm{pH}$ (as the calcium concentrations decrease at higher $\mathrm{pH}$-values due to the precipitation of portlandite). At longer hydration times, where no longer gypsum and anhydrite but ettringite limits the sulfate concentrations, much lower sulfate concentrations are observed and the influence of $\mathrm{pH}$ is relatively weak.

\subsubsection{Silicon and aluminium concentrations}

The concentrations of aluminium and silicon in the pore solution are in most cases below $1 \mathrm{mmol} / \mathrm{l}$.
Exceptionally high silicon concentrations of up to $4.6 \mathrm{mmol} / \mathrm{l}$ are reported in [31]. These values were determined by X-ray fluorescence (XRF) analysis after dripping drops of pore solution on filter paper. This method is probably not reliable for low concentrated elements like silicon and therefore this data was excluded. The remaining data points were analysed in the same way as for sulfate and calcium, since the concentrations do not depend significantly on $w / c$ ratio (Fig. 11). The scatter is about two orders of magnitude. It might be reasonably assumed that most of this deviation is caused by analytical errors although also 

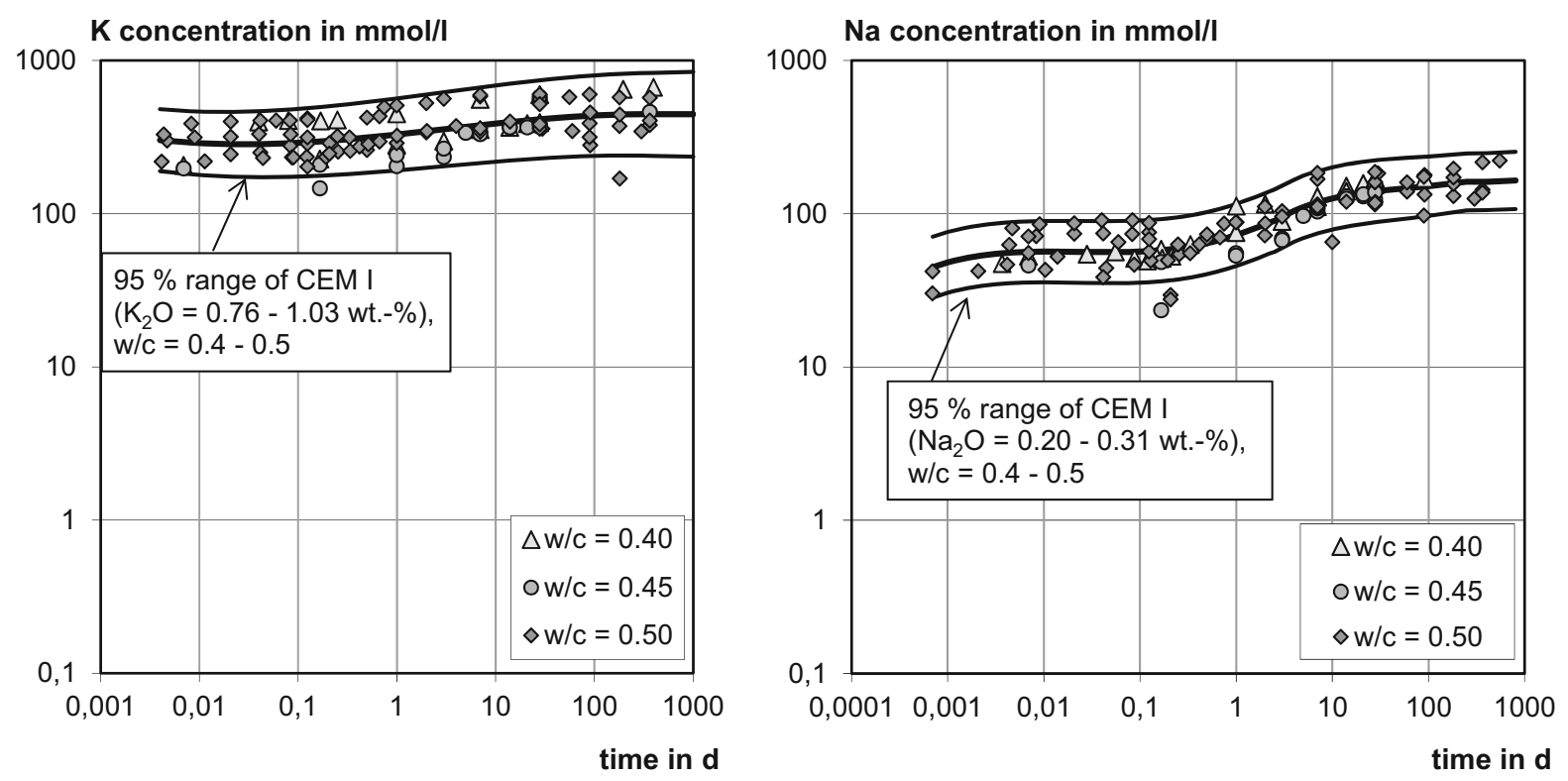

Fig. 6 Statistical evaluation of potassium and sodium concentrations in the pore solution of pure PC pastes with a $\mathrm{K}_{2} \mathrm{O}$ content of the cement $0.76-1.03 \mathrm{wt} \%[6,7,11,12,16-19,23,31,35,36,38,40,42]$

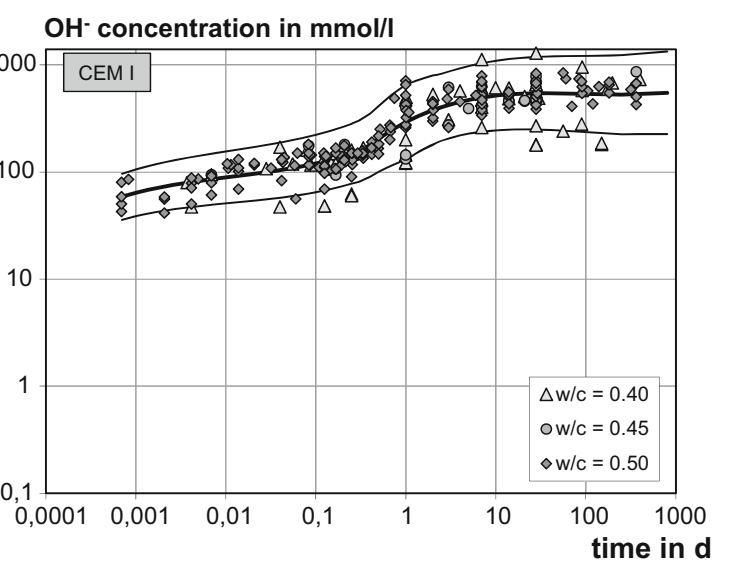

Fig. 7 Statistical evaluation of hydroxide concentrations in the pore solution of pure PC pastes $[3,6,9,11,12,15-23,28,36,38$, 39, 42]

different $\mathrm{pH}$-values and thus calcium concentrations will have an influence. As in many cases a detection limit of $0.1-1 \mathrm{mg} / \mathrm{l}(\approx 0.036 \mathrm{mmol} / \mathrm{l})$ seems reasonable, some of the very low measurements may not be reliable and associated with large errors.

The aluminium concentrations are slightly lower than the silicon concentrations and show a similar scatter (Fig. 11, right). A slight increase is observed for both aluminium and silicon as the $\mathrm{pH}$ rises after the depletion of the calcium sulfate.

\subsection{Blends with GGBS}

\subsubsection{Alkali and hydroxide concentrations}

Blast furnace slags generally contain less alkali compounds than PC clinker, which leads to lower potassium and sodium concentrations in GGBS blended cements as shown in Fig. 12. For slag contents $\leq 40 \%$ the concentrations are usually within the range of pure CEM I pastes.

Figure 12, bottom, shows the hydroxide concentrations, which are lower in the presence of high slag contents. In addition to the lower alkali concentrations also reduced sulfur species such as sulfide $\left(\mathrm{HS}^{-}\right)$, sulfite $\left(\mathrm{SO}_{3}^{2-}\right)$ and thiosulfate $\left(\mathrm{S}_{2} \mathrm{O}_{3}^{2-}\right)$ can lower the $\mathrm{pH}$ of GGBS blend pore solutions [24]. GGBS contains about $1-2 \mathrm{wt} \%$ of $\mathrm{S}^{2-}$ (mean value of the GGBS included in the database $1.12 \mathrm{wt} \%$ ), which leads to the formation of reduced sulfur species in the pore solution.

\subsubsection{Calcium and sulfur concentrations}

The calcium concentrations in the pore solution of GGBS blends are shown in Fig. 13. No significant difference compared to pure CEM I pastes is observed even for high slag contents. 

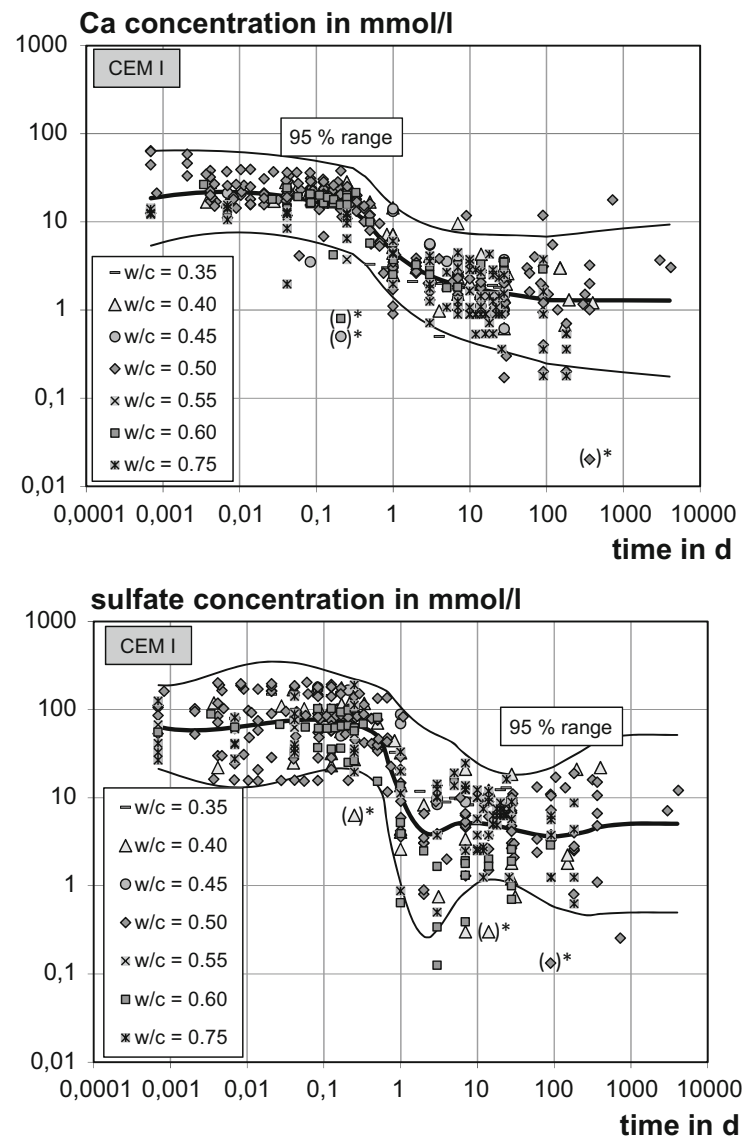

Fig. 8 Statistical evaluation of calcium and sulfate concentrations in the pore solution of pure PC pastes [1, 3, 5-9, 11-18, 2023, 26, 28-30, 32, 35-39, 42], *outlier

\section{Ca concentration in $\mathrm{mmol} / \mathrm{l}$}

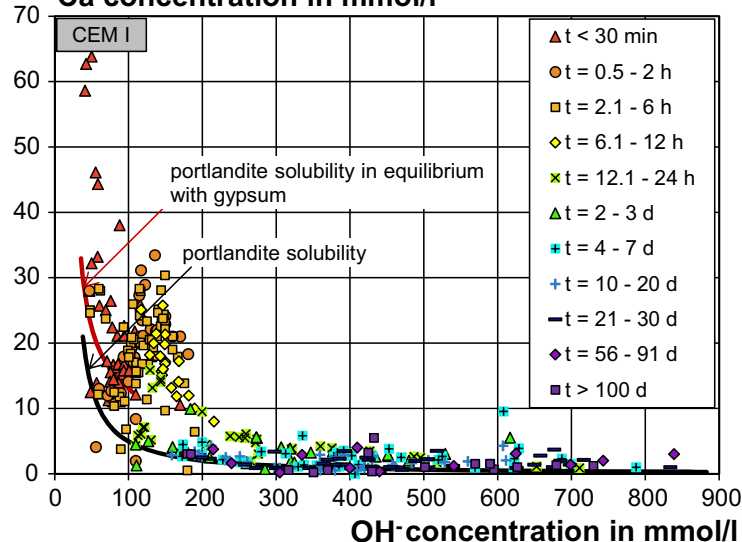

Fig. 9 Calcium concentrations as a function of the $\mathrm{OH}^{-}$ concentration, [3, 6, 9, 11, 12, 15-18, 20-23, 28, 36, 38, 39, 42]

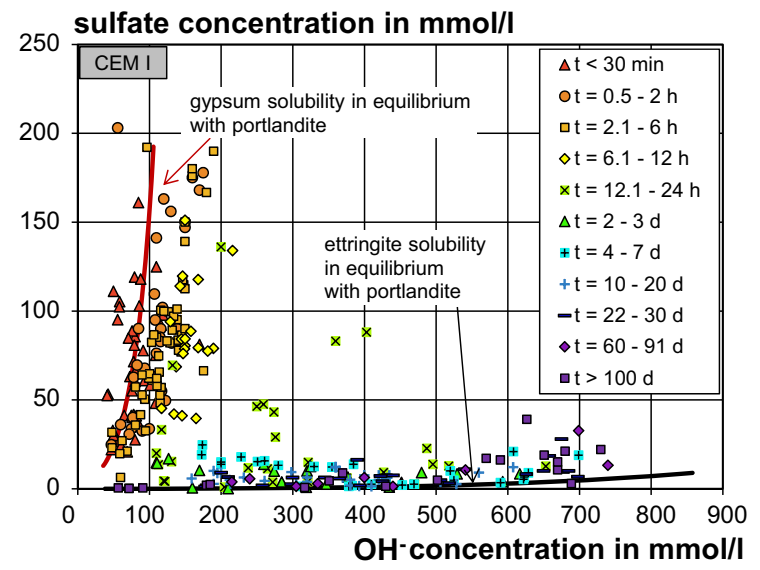

Fig. 10 Sulfate concentrations as a function of the $\mathrm{OH}^{-}$ concentration $[3,6,11,12,17,18,29,36,38,39,42]$ at early (presence of gypsum and portlandite) and later hydration times (presence of ettringite and portlandite)

Most of the results from the database for sulfate/sulfur in the pore solution of binders with GGBS were obtained with IC. This method measures the sulfate concentration (see Fig. 14, left). Due to the other sulfur species present in the pore solution of slag cements, the molar concentration of sulfur $S_{\text {tot }}$ as determined by ICPOES can be higher than the sulfate concentration especially at later ages [24], as in addition to sulfate also thiosulfate can be present (as the solutions are generally acidified before ICP-OES measurements, the volatile sulfur species $\mathrm{H}_{2} \mathrm{~S}, \mathrm{SO}_{2}$ and $\mathrm{SO}_{3}$ evaporate before the measurement). In addition, storage times can lead to oxidation of the reduced sulfur species. Therefore literature results for sulfate and total sulfur may not always represent the original concentrations. The available data for slag cements show no significant difference between sulfate and total sulfur (see Fig. 14). Detailed investigations of the different sulfur species in [24] showed that at later ages ( $\geq 56$ days) only $20-30 \%$ of the total sulfur is in the form of sulfate (these results are for a ternary blend with nanosilica and are therefore not included in Fig. 14).

\subsubsection{Silicon and aluminium concentrations}

Figure 15 shows the concentrations of silicon and aluminium in the pore solution of GGBS blends. During the first year of hydration the concentrations 

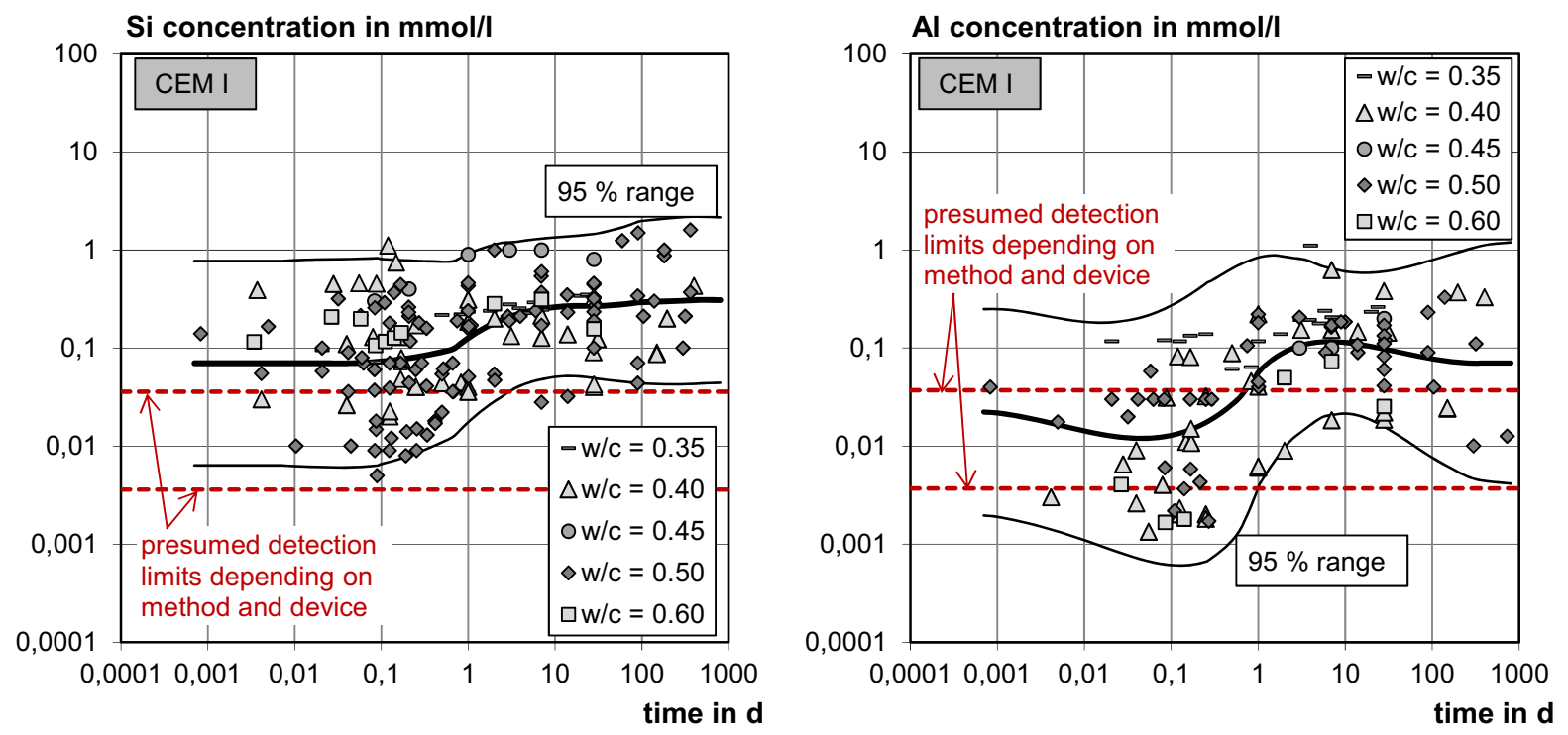

Fig. 11 Statistical evaluation of silicon and aluminium concentrations in the pore solution of pure PC pastes $[1,3,6,7,13,17,18,20-$ $23,30,37-39,42]$

are in the same range as for pure CEM I pastes. For later ages no data is available.

In summary, the presence of GGBS slightly lowers the alkali concentration and $\mathrm{pH}$-values of the pore solution, that can lead to the presence of reduced sulfur species [21]. High amounts of GGBS ( $>75 \mathrm{wt} \%$ of the binder) can have a strong influence on the alkalinity. The effect on the other ions in the pore solution is relatively small.

\subsection{Blends with FA}

\subsubsection{Alkali and hydroxide concentrations}

The concentrations of potassium and sodium are shown in Fig. 16. Potassium concentrations in the pore solution of FA blended pastes are lower compared to CEM I pastes, especially after long hydration times. Sodium concentrations are usually in the same range. The decrease of the alkali concentrations with time is related to the reaction of the FA, which not only releases more alkalis but results in the formation of $\mathrm{C}-$ $\mathrm{S}-\mathrm{H}$ with a lower $\mathrm{Ca} / \mathrm{Si}$ ratio, where the alkalis are bound. The uptake of aluminium in the $\mathrm{C}-\mathrm{S}-\mathrm{H}$ contributes to alkali binding $(\mathrm{C}-\mathrm{A}-\mathrm{S}-\mathrm{H})$.

Alkali concentrations in the pore solution depend strongly on the total alkali content of the cement and FA which are used. Based on the information given in the references the total content of $\mathrm{K}_{2} \mathrm{O}$ and $\mathrm{Na}_{2} \mathrm{O}$ of the binders were calculated, respectively (see Eq. 2).

$\left(\mathrm{K}_{2} \mathrm{O}\right)_{\mathrm{b}}=\left(\mathrm{K}_{2} \mathrm{O}\right)_{\mathrm{c}} \cdot a_{\mathrm{c}} / 100+\left(\mathrm{K}_{2} \mathrm{O}\right)_{\mathrm{f}} \cdot a_{\mathrm{f}} / 100$,

$\left(\mathrm{K}_{2} \mathrm{O}\right)_{\mathrm{b}}$ is the potassium content of the binder in $\mathrm{wt} \%,\left(\mathrm{~K}_{2} \mathrm{O}\right)_{\mathrm{c}}$ is the potassium content of the cement (CEM I) in wt $\%,\left(\mathrm{~K}_{2} \mathrm{O}\right)_{\mathrm{f}}$ is the potassium content of the $\mathrm{FA}$ in $\mathrm{wt} \%, a_{\mathrm{c}}$ is the cement content of the binder in wt $\%$ and $a_{\mathrm{f}}$ is the FA content of the binder in wt $\%$.

In Fig. 17 the concentrations in the pore solution after 7 and 365 days of hydration are plotted against the total contents.

An increase of the alkali concentrations in the pore solution with increasing total alkali content is observed for all binders. With increasing FA replacement the alkali concentrations in the pore solution decrease continuously. This trend to lower alkali concentration is accentuated during hydration, as the alkalis which are released from the dissolving FA are bound to the reaction products. The pozzolanic reaction leads to $\mathrm{C}-\mathrm{A}-\mathrm{S}-\mathrm{H}$ phases with lower $\mathrm{Ca} / \mathrm{Si}$ ratio, which take up more alkalis than high $\mathrm{Ca} / \mathrm{Si} \mathrm{C}-\mathrm{S}-\mathrm{H}$ [78, 83].

This increased uptake of the alkalis in $\mathrm{C}-\mathrm{A}-\mathrm{S}-\mathrm{H}$ leads to a decrease of the hydroxide concentrations at longer hydration times (see Fig. 18). 

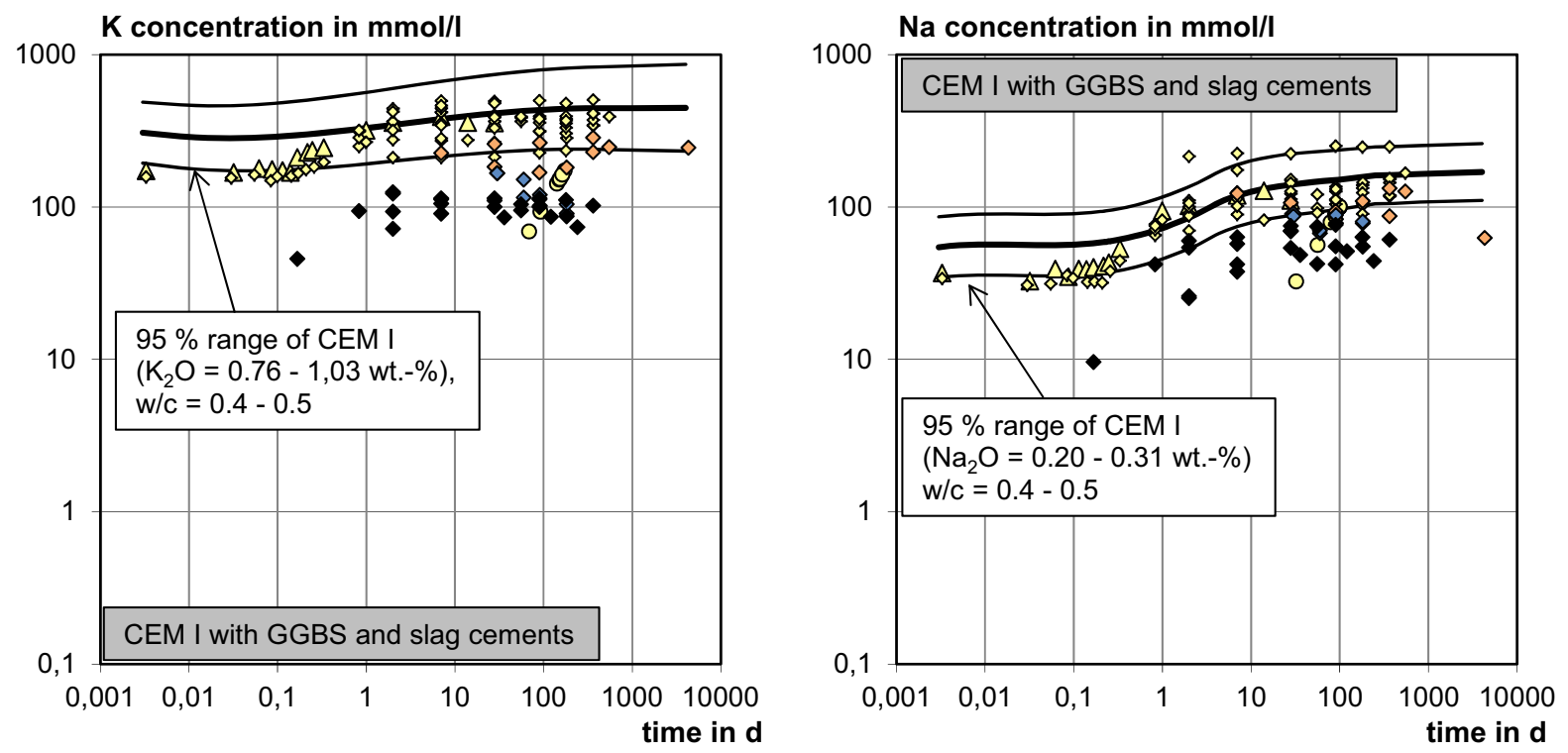

\section{$\mathrm{OH}^{-}$concentration in $\mathrm{mmol} / \mathrm{l}$}

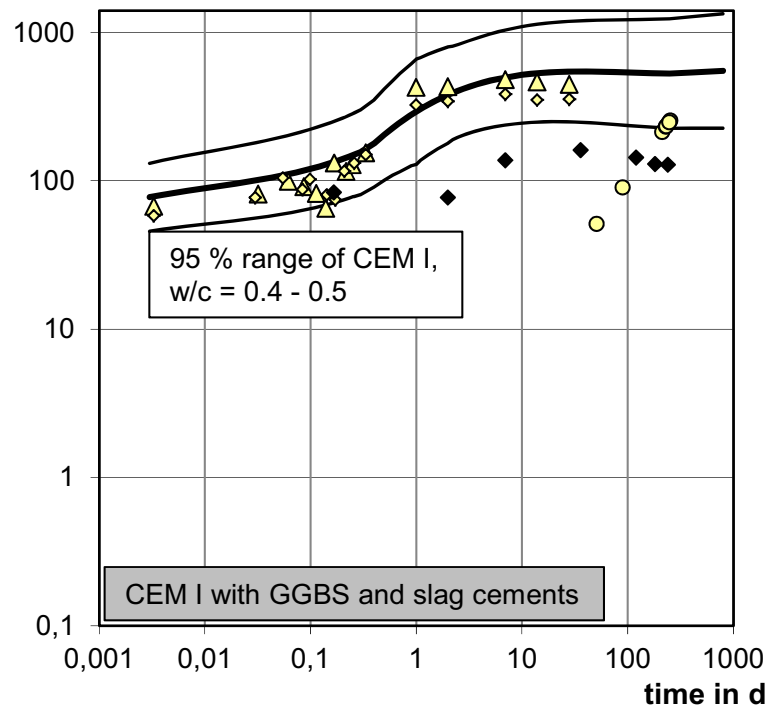

Fig. 12 Potassium, sodium and hydroxide concentrations in the pore solution of GGBS blended cement pastes compared to the $95 \%$ range of CEM I, calculated in Sect. 3.1.2 [5, 11, 18, 31-36, 40, 42]

\subsubsection{Calcium and sulfate concentrations}

Calcium and sulfate concentrations in the pore solution of FA blends are mostly in the same range as observed for pure CEM I pastes (see Fig. 19). Some very low sulfate concentrations are observed between 1 and 28 days, which cannot be explained.

\subsubsection{Silicon and aluminium concentrations}

The concentrations of silicon in the pore solution are in the same range as for pure CEM I pastes (Fig. 20). For aluminium a slightly different trend is observed: the concentrations seem to increase over time. This trend has been related to the reaction of FA, which contains 
Fig. 13 Calcium concentrations in the pore solution of GGBS blended cement pastes compared to the $95 \%$ range of CEM I, calculated according to Sect. 3.1.1 [5, 11, 18, 32-36, 42]

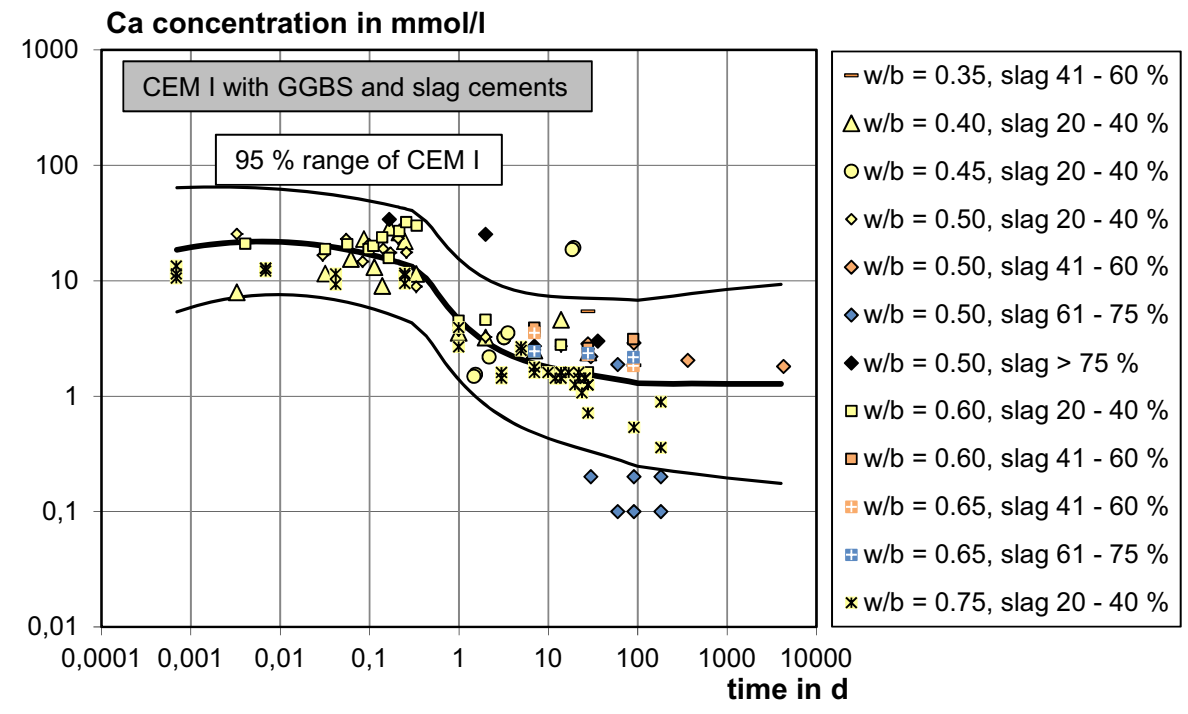

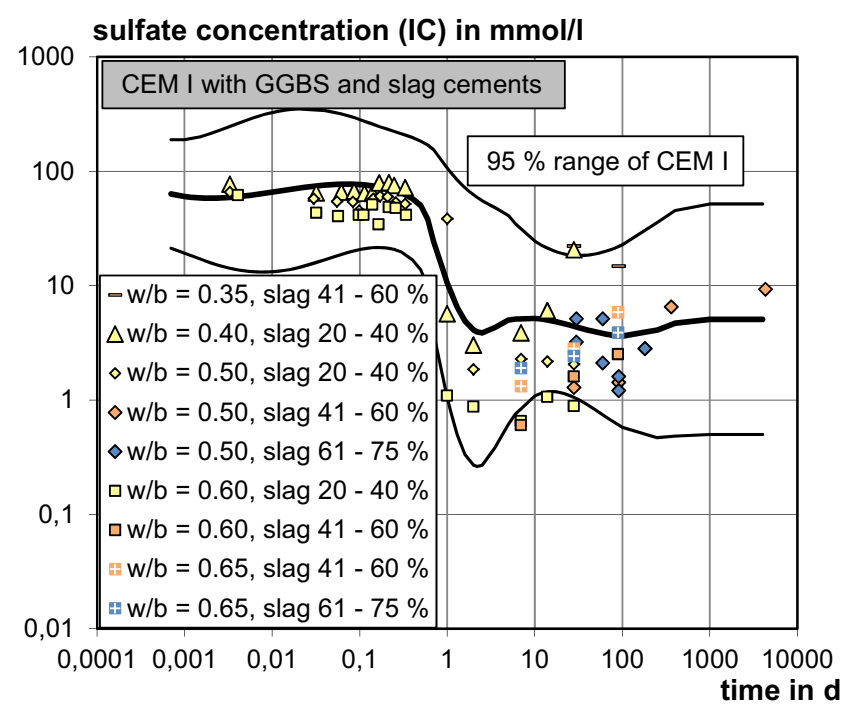

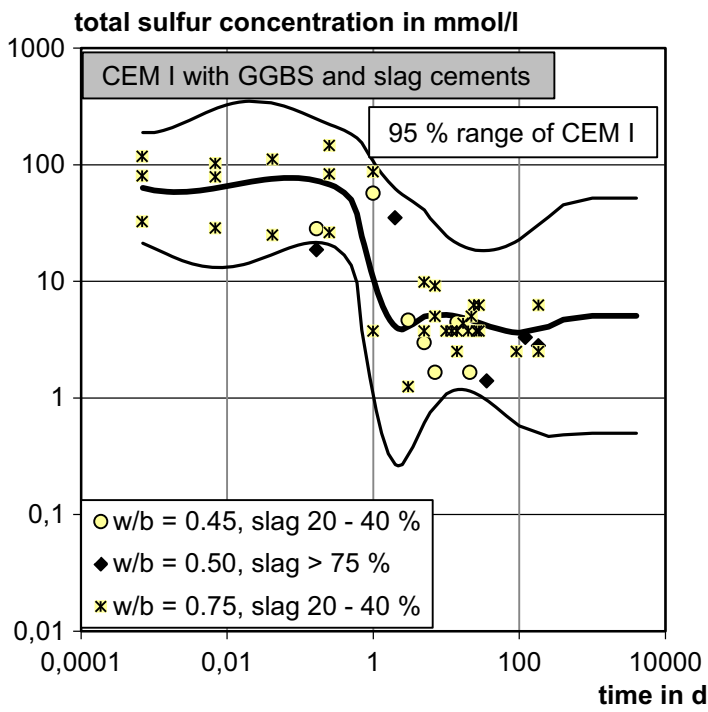

Fig. 14 Sulfate (as determined by IC measurements) and sulfur (determined by ICP-OES) concentrations in the pore solution of GGBS blended cement pastes compared to the $95 \%$ range of CEM I, calculated according to Sect. 3.1 .1 [5, 11, 18, 32-36, 42]

more aluminium than PC [10]. Unfortunately there is no data for very long hydration times ( $>365$ days) to confirm this trend.

\subsection{Blends with SF}

\subsubsection{Alkali and hydroxide concentrations}

The blending of PC with SF lowers the alkali and hydroxide concentrations in the pore solution significantly (see Fig. 21). The strong pozzolanic reaction increases the amount of $\mathrm{C}-\mathrm{S}-\mathrm{H}$ formed and leads to the formation of $\mathrm{C}-\mathrm{S}-\mathrm{H}$ phases with lower $\mathrm{Ca} /$ Si ratio. These $\mathrm{C}-\mathrm{S}-\mathrm{H}$ phases take up more alkalis $[78$, 83]. Due to the higher reaction degree of SF compared to FA and the higher silicon content, the reduction of alkalis is much stronger than for FA (compare Fig. 16). At very high SF replacement levels portlandite is completely consumed, low $\mathrm{Ca} / \mathrm{Si} \mathrm{C}-\mathrm{S}-\mathrm{H}$ is present and more alkalis are bound [5, 74]. 

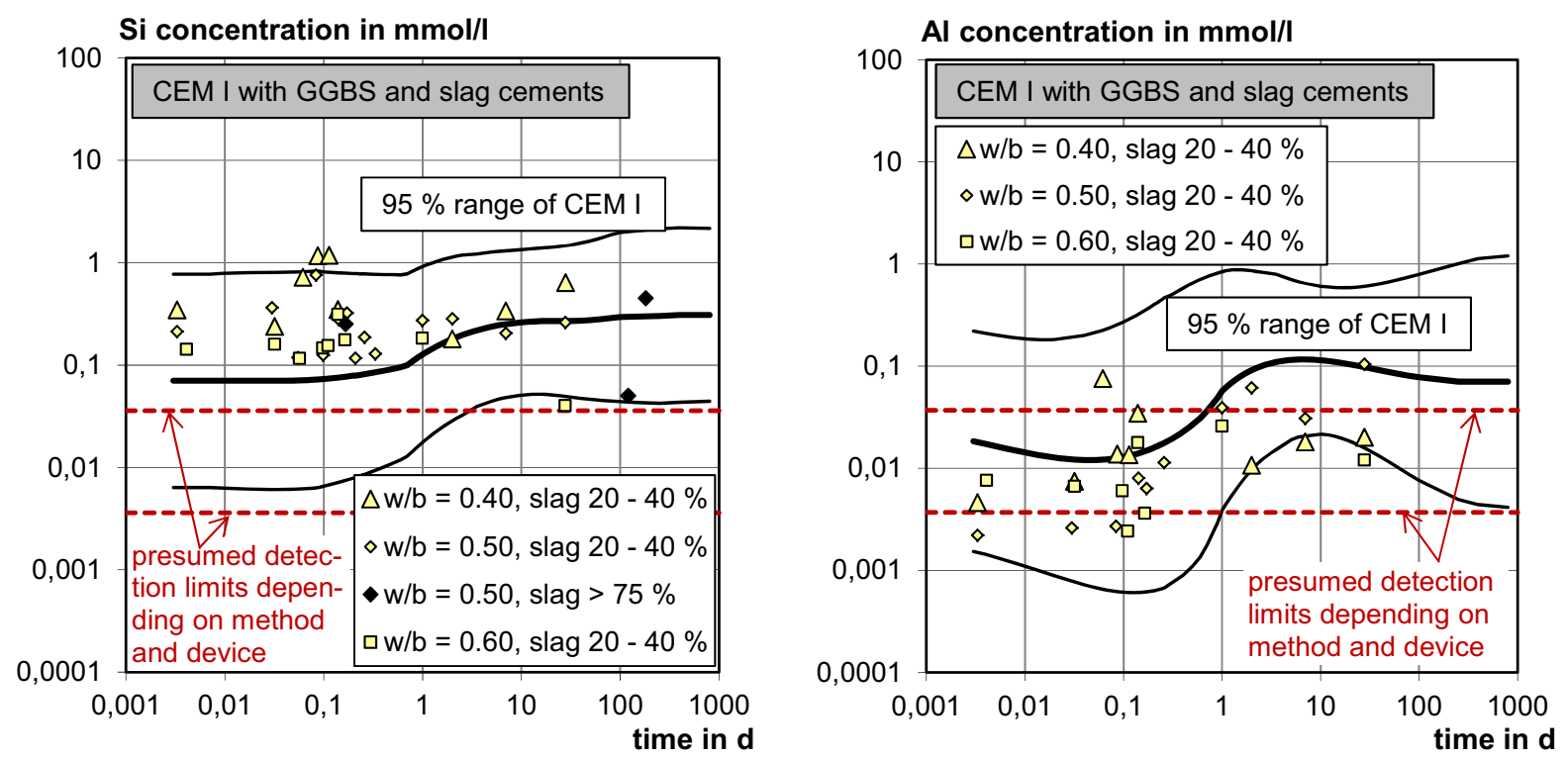

Fig. 15 Silicon and aluminium concentrations in the pore solution of GGBS blended cement pastes compared to the $95 \%$ range of CEM I, calculated in Sect. 3.1.4 [18, 36, 42]

\subsubsection{Calcium and sulfate concentrations}

The concentrations of calcium and sulfate in the pore solution are often out of the range of pure CEM I pastes (see Fig. 22). One would expect that calcium concentrations are reduced once portlandite is depleted, but instead they increase at high replacement ratios, because the $\mathrm{pH}$-value decreases significantly.

In contrast to studies on synthetic $\mathrm{C}-\mathrm{S}-\mathrm{H}$ phases where the presence of low $\mathrm{Ca} / \mathrm{Si} \mathrm{C}-\mathrm{S}-\mathrm{H}$ generally results in high silicon and low calcium concentrations, the situation in cements is complicated by the presence of alkali ions. The formation of low $\mathrm{Ca} / \mathrm{Si} \mathrm{C}-\mathrm{S}-\mathrm{H}$ lowers the alkali concentration and thus the $\mathrm{pH}$ of the pore solution. The solubility product of $\mathrm{C}-\mathrm{S}-\mathrm{H}$ for the reaction shown in Eq. 3, from [69] for low $\mathrm{Ca} / \mathrm{Si} \mathrm{C}-\mathrm{S}-$ $\mathrm{H}$ indicates that a decrease of the hydroxide concentration is expected to lead to an increase of calcium and/or silicon concentration.

$$
\begin{aligned}
& \frac{2}{3} \mathrm{Ca}^{2+}+\mathrm{Si}(\mathrm{OH})_{4}^{0}+\frac{4}{3} \mathrm{OH}^{-}-\frac{7}{8} \mathrm{H}_{2} \mathrm{O} \\
& \leftrightarrow(\mathrm{CaO})_{0.67} \mathrm{SiO}_{2}\left(\mathrm{H}_{2} \mathrm{O}\right)_{1.5} \\
& K_{\mathrm{sp}}=10^{-10.38} .
\end{aligned}
$$

Figure 23 shows the correlation between calcium concentration and $\mathrm{pH}$-value for all the binders considered in this paper. It is obvious that the SF blends with more than $30 \% \mathrm{SF}$ are out of the usual $\mathrm{pH}$ range (i.e., they are undersaturated with respect to portlandite) and there is a trend towards higher calcium concentrations at lower $\mathrm{pH}$. This tendency is also observed in leaching experiments as shown in Fig. 23.

\subsubsection{Silicon and aluminium concentrations}

The concentrations of silicon and aluminium in the pore solution are in the same range as for pure CEM I pastes (Fig. 24).

\section{Thermodynamic modelling}

Thermodynamic modelling is used to calculate the impact of the SCM replacement level on the pore solution composition and the solid hydrate assemblage. The calculated pore solution compositions are compared to literature experimental data for verification and differences are discussed. The observed trends are explained in terms of the impact of the SCMs on the modelled hydrate assemblage for FA and SF blended cements.

In addition to the effect of hydration time and of the composition of the SCM, also the amount of SCM in 
Fig. 16 Potassium and sodium concentrations in the pore solution of FA blended cement pastes compared to the $95 \%$ range of CEM I, calculated in Sect. 3.1.2 [1, $3,5,9-11,15,19,26,27$, $31-33,39,40,42]$

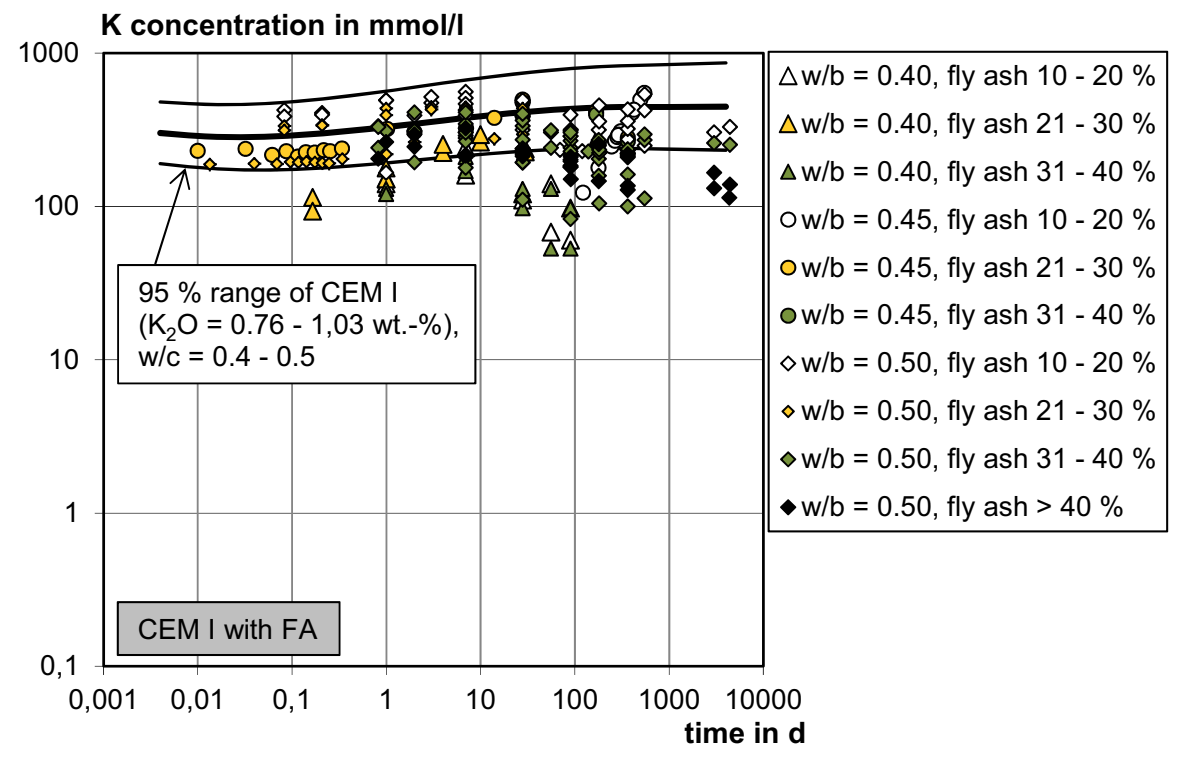

$\mathrm{Na}$ concentration in $\mathrm{mmol} / \mathrm{l}$

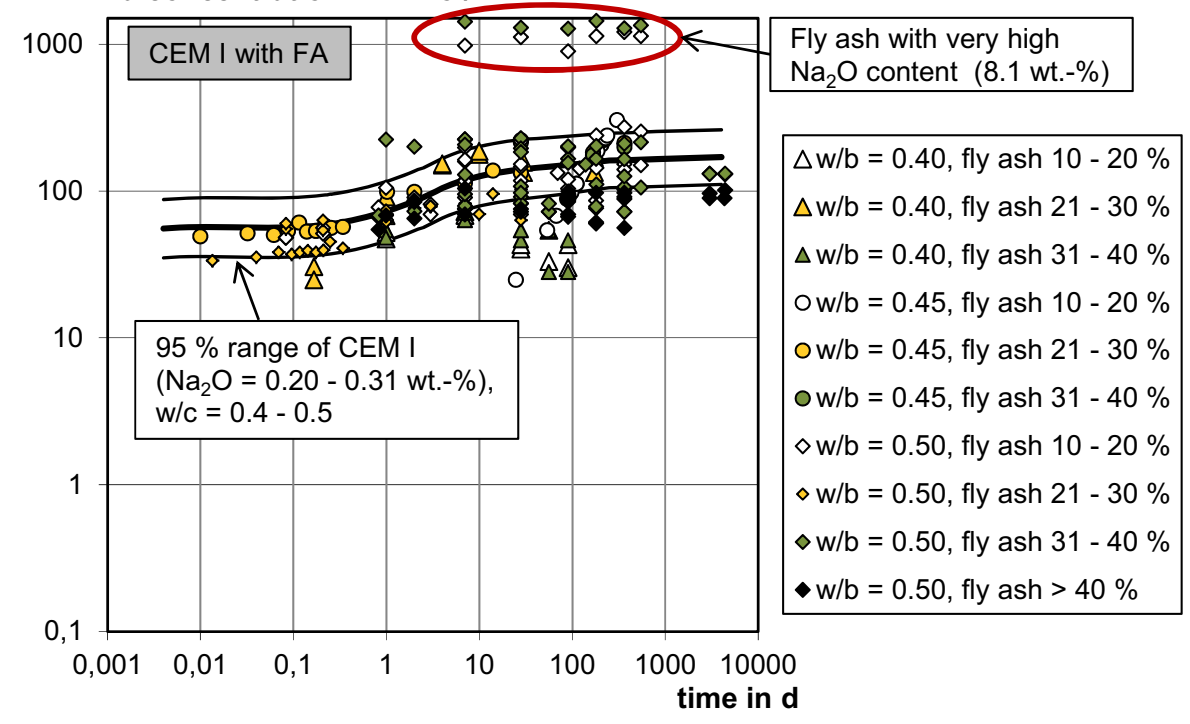

the blend has an important impact on the composition of the pore solution and the solid phase assemblage. Experimental data for longer hydration times, obtained from the literature, are compared to predictions of the pore solution composition using thermodynamic modelling.

For FA experimental data for a blending of up to 60 wt $\%$ FA were available $[3,5,10,31,39]$. Two hydration stages, i.e., 28-90 days and 12 years, representing different DoRs are summarised. Correspondingly, different degrees of FA reaction (10-30\% after 28 days and $25-50 \%$ after 12 years, depending on the FA content cf. Fig. 2) are assumed for the modelling. The chemical data of cement and FA used for modelling is described in Table 3.

The effect of blending SF into PC on pore solution composition was calculated for a SF content of up to 35 wt $\%$ of the binder at 28 days and for $\geq 150$ days using the average chemical composition on the raw materials used in literature $[5,7,25,28,31,40,41]$ (cf. Table 4). 
Fig. 17 Potassium and sodium concentrations in the pore solution after 7 and 365 days of hydration depending on the total content of $\mathrm{K}_{2} \mathrm{O}$ and $\mathrm{Na}_{2} \mathrm{O}$, respectively $[3$, $10,11,15,19,26,27,31,32$, $39,40,42]$ concentration in the pore solution in $\mathrm{mmol} / \mathrm{l}$

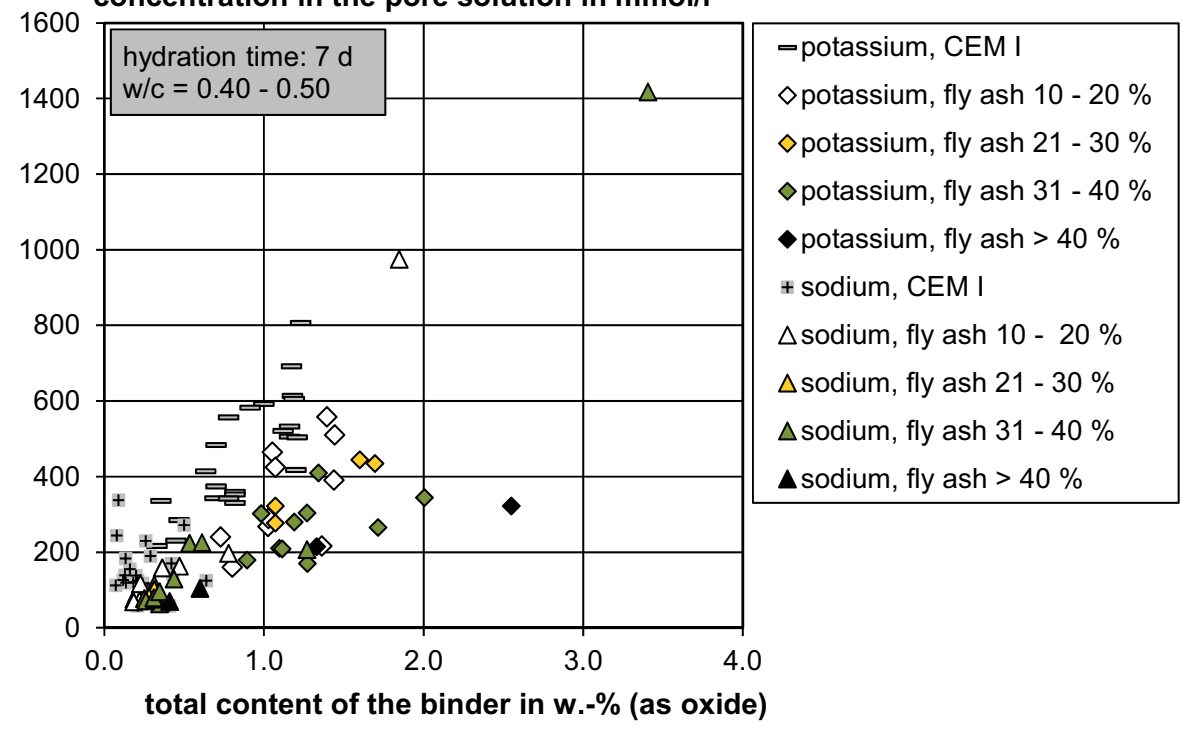

concentration in the pore solution in $\mathrm{mmol} / \mathrm{l}$

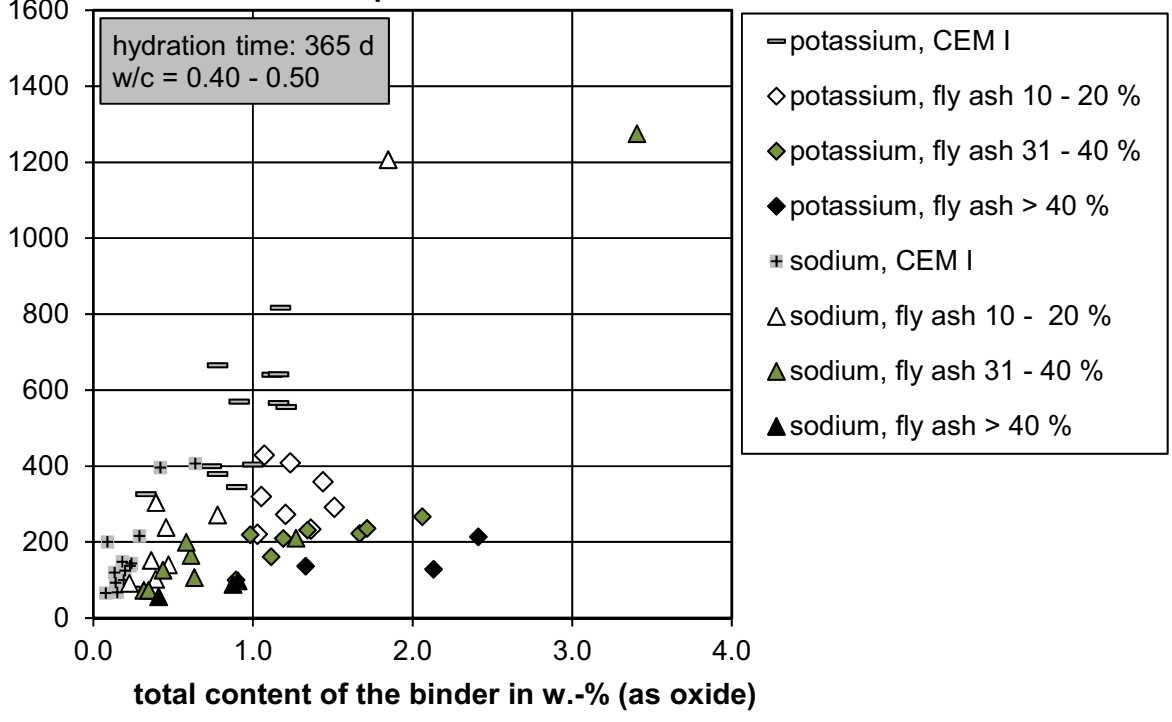

For the modelling 60 and $80 \%$ DoR of the SF was assumed at 28 and at $\geq 150$ days regardless of the replacement level (cf. Fig. 2).

\subsection{Fly ash}

The main effect of the presence of FA and SF (see next section) on the pore solution after longer reaction times is the lowering of the alkali and hydroxide concentrations as shown in Fig. 25. For FA, an increase of the aluminium concentration and a decrease of the calcium concentration at higher replacement levels are also observed. The data measured after 1-3 months and after 12 years are very similar consistent with the very slow reaction of FA.

The thermodynamic modelling predicts less portlandite if PC is replaced by FA, and above $40 \mathrm{wt} \%$ of FA the absence of portlandite and the formation of $\mathrm{C}-$ $\mathrm{S}-\mathrm{H}$ with lower $\mathrm{Ca} / \mathrm{Si}$ ratio as illustrated by the increasing fractions of the more Si-rich C-S-H endmembers in Fig. 25, bottom. In hydration studies, generally a decrease of the $\mathrm{Ca} / \mathrm{Si}$ ratio of the $\mathrm{C}-\mathrm{S}-\mathrm{H}$ 
Fig. 18 Hydroxide concentrations in the pore solution of FA blended cement pastes compared to the $95 \%$ range of CEM I, calculated in Sect. 3.1.2 [3, 9-11, 15, 19, 27, 39, 42]

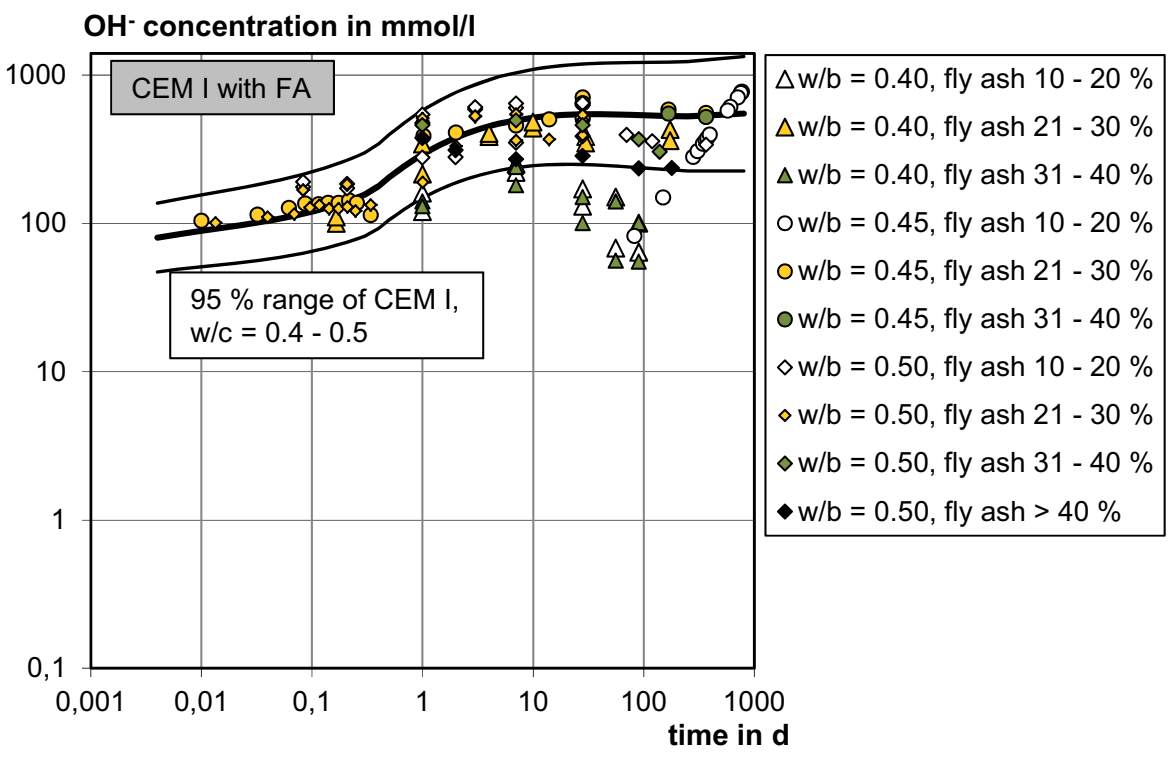

and lowering of the portlandite content is observed but not a complete depletion of portlandite [10, 39, 74] even after 12 years of hydration. The resilience of portlandite in hydrating FA-PC blends has been explained by the inhomogeneity of the microstructure and the lack of water. These changes in the solid phase composition are mirrored in the calculated decrease of calcium concentrations at higher replacement ratios, which agrees well with the experimental data both after 1-3 months and after 12 years. In parallel an increase of the silicon concentration is predicted, which could not be verified due to a lack of experimental silicon measurements.

The portlandite depletion also marks a significant decrease of the alkali concentrations and the $\mathrm{pH}$-values.
The steep drop in the calculated alkali content of the pore solution reflects the increased uptake of alkalis in more Si-rich C-S-H phases as observed experimentally on synthetic $\mathrm{C}-\mathrm{S}-\mathrm{H}[78,83]$. The general decrease of the alkali and hydroxide concentrations predicted by the thermodynamic model agrees well with the experimental data, except in the case of sodium, where the experimental data show no decrease.

Beyond portlandite depletion lower calcium and higher aluminium and silicon concentrations result in the formation of strätlingite $\left(2 \mathrm{CaO} \cdot \mathrm{Al}_{2} \mathrm{O}_{3} \cdot \mathrm{SiO}_{2} \cdot 8 \mathrm{H}_{2} \mathrm{O}\right)$ instead of monocarbonate. Ettringite and hydrotalcite are predicted to be stable over the explored range of blending. Slightly decreasing volume fractions are related to the dilution of the $\mathrm{PC}$ component.

Table 3 Chemical composition of cement and fly ash used for modelling

\begin{tabular}{llllllllllll}
\hline Materials & $\begin{array}{l}\mathrm{SiO}_{2} \\
\mathrm{wt} \%\end{array}$ & $\begin{array}{l}\mathrm{Al}_{2} \mathrm{O}_{3} \\
\mathrm{wt} \%\end{array}$ & $\begin{array}{l}\mathrm{Fe}_{2} \mathrm{O}_{3} \\
\mathrm{wt} \%\end{array}$ & $\begin{array}{c}\mathrm{CaO} \\
\mathrm{wt} \%\end{array}$ & $\begin{array}{l}\mathrm{MgO} \\
\mathrm{wt} \%\end{array}$ & $\begin{array}{l}\mathrm{K}_{2} \mathrm{O} \\
\mathrm{wt} \%\end{array}$ & $\begin{array}{l}\mathrm{Na}_{2} \mathrm{O} \\
\text { wt\% }\end{array}$ & $\begin{array}{l}\mathrm{SO}_{3} \\
\text { wt\% }\end{array}$ & $\begin{array}{l}\mathrm{TiO}_{2} \\
\text { wt\% }\end{array}$ & $\begin{array}{l}\mathrm{P}_{2} \mathrm{O}_{5} \\
\text { wt\% }\end{array}$ & $\begin{array}{l}\mathrm{CO}_{2} \\
\text { wt\% }\end{array}$ \\
\hline $\mathrm{PC}$ & 19.51 & 5.37 & 2.96 & 63.15 & 1.57 & 1.00 & 0.25 & 4.13 & 0.26 & 0.14 & 0.54 \\
FA & 48.64 & 26.88 & 8.14 & 4.51 & 1.95 & 2.74 & 0.81 & 0.69 & 1.20 & 0.64 & - \\
\hline
\end{tabular}

Table 4 Chemical composition of cement and silica fume used for modelling

\begin{tabular}{llllllllllll}
\hline Materials & $\begin{array}{l}\mathrm{SiO}_{2} \\
\mathrm{wt} \%\end{array}$ & $\begin{array}{l}\mathrm{Al}_{2} \mathrm{O}_{3} \\
\mathrm{wt} \%\end{array}$ & $\begin{array}{l}\mathrm{Fe}_{2} \mathrm{O}_{3} \\
\mathrm{wt} \%\end{array}$ & $\begin{array}{c}\mathrm{CaO} \\
\mathrm{wt} \%\end{array}$ & $\begin{array}{l}\mathrm{MgO} \\
\text { wt\% }\end{array}$ & $\begin{array}{l}\mathrm{K}_{2} \mathrm{O} \\
\text { wt\% }\end{array}$ & $\begin{array}{l}\mathrm{Na}_{2} \mathrm{O} \\
\text { wt\% }\end{array}$ & $\begin{array}{l}\mathrm{SO}_{3} \\
\text { wt\% }\end{array}$ & $\begin{array}{l}\mathrm{TiO}_{2} \\
\text { wt\% }\end{array}$ & $\begin{array}{l}\mathrm{P}_{2} \mathrm{O}_{5} \\
\text { wt\% }\end{array}$ & $\begin{array}{l}\mathrm{CO}_{2} \\
\text { wt\% }\end{array}$ \\
\hline $\mathrm{PC}$ & 20.41 & 5.06 & 2.90 & 64.02 & 1.76 & 0.81 & 0.26 & 2.89 & 0.16 & 0.09 & 0.99 \\
$\mathrm{SF}$ & 91.85 & 0.44 & 2.01 & 1.20 & 0.69 & 0.71 & 0.32 & 0.14 & 0.06 & 0.02 & - \\
\hline
\end{tabular}


Fig. 19 Calcium and sulfate concentrations in the pore solution of FA blended cement pastes compared to the $95 \%$ range of CEM I, calculated according to Sect. 3.1.1 [1,3, 5, 9-11, 15, $26,32,33,39,42]$

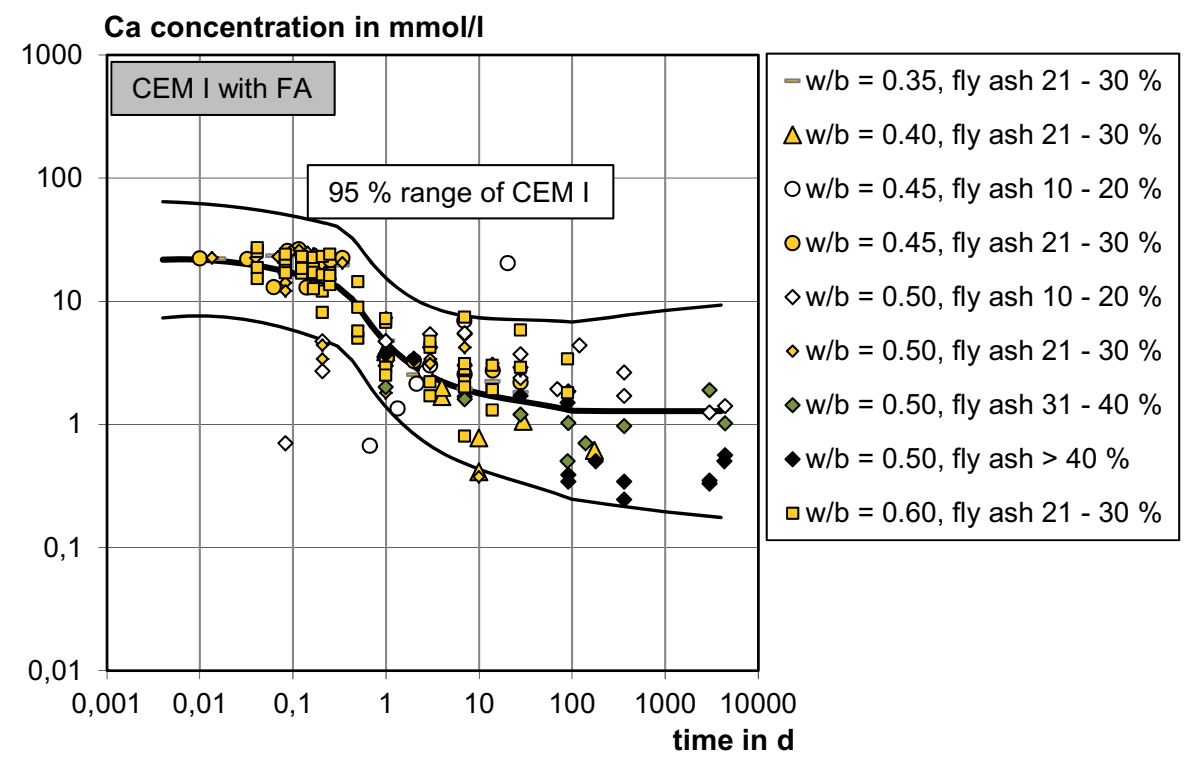

sulfate concentration in $\mathrm{mmol} / \mathrm{l}$

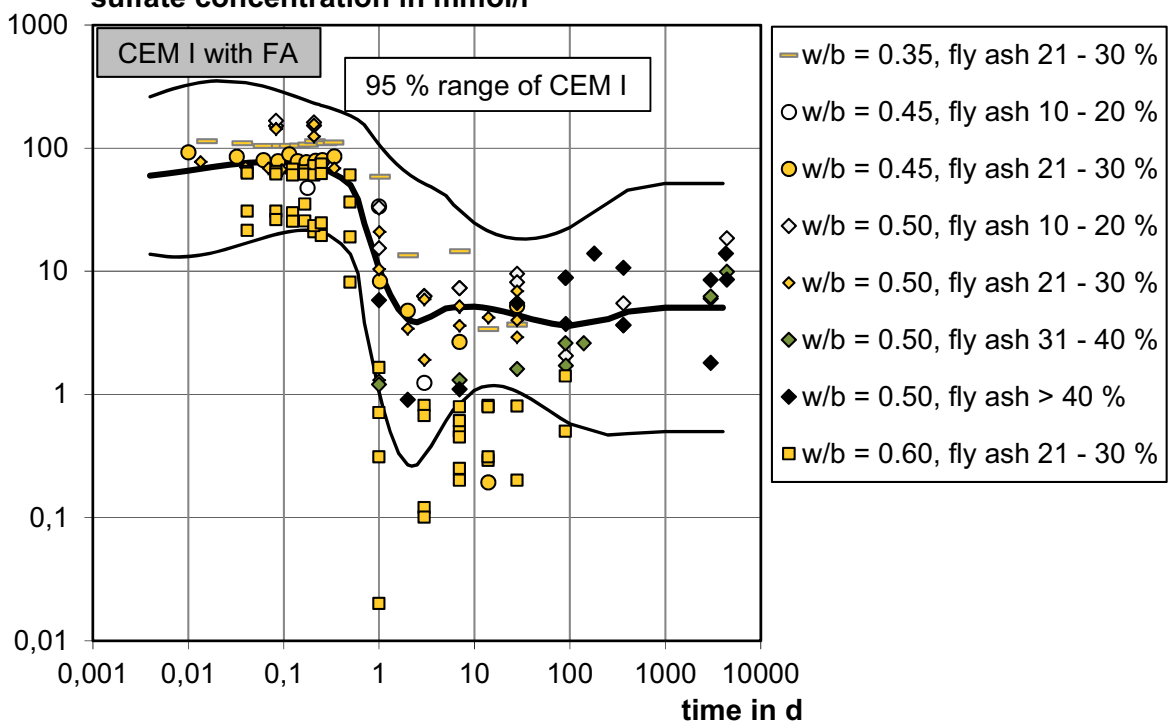

The aluminium and sulfate concentrations are controlled by the solubility of ettringite and thus increase as the calcium concentration and $\mathrm{pH}$-values decrease.

\subsection{Silica fume}

The decrease of the alkali and hydroxide concentrations is much stronger in the presence of SF as shown in Fig. 26. With time as more SF reacts, the decrease of alkali and hydroxide concentrations becomes more distinct.

As for FA, the thermodynamic modelling predicts the decrease of the portlandite content if PC is replaced by SF. Above $20 \mathrm{wt} \%$ of SF the absence of portlandite and the formation of more $\mathrm{C}-\mathrm{S}-\mathrm{H}$ with lower $\mathrm{Ca} / \mathrm{Si}$ ratio is predicted as illustrated in Fig. 26, bottom. Again the portlandite depletion marks the significant decrease of the alkali concentrations and of $\mathrm{pH}$-values. The modelling predicts lower alkali and hydroxide concentrations than in the case of FA, as more $\mathrm{C}-\mathrm{S}-\mathrm{H}$ is predicted to form, which increases the alkali binding. The general decrease of the alkali and hydroxide concentrations predicted by the thermodynamic model agrees well with the experimental data, although the calculations overestimate the alkali and hydroxide concentrations at higher replacement levels. 
Fig. 20 Silicon and aluminium concentrations in the pore solution of FA blended cement pastes compared to the $95 \%$ range of CEM I, calculated in Sect. 3.1.4 [3, 10, 39, 42]
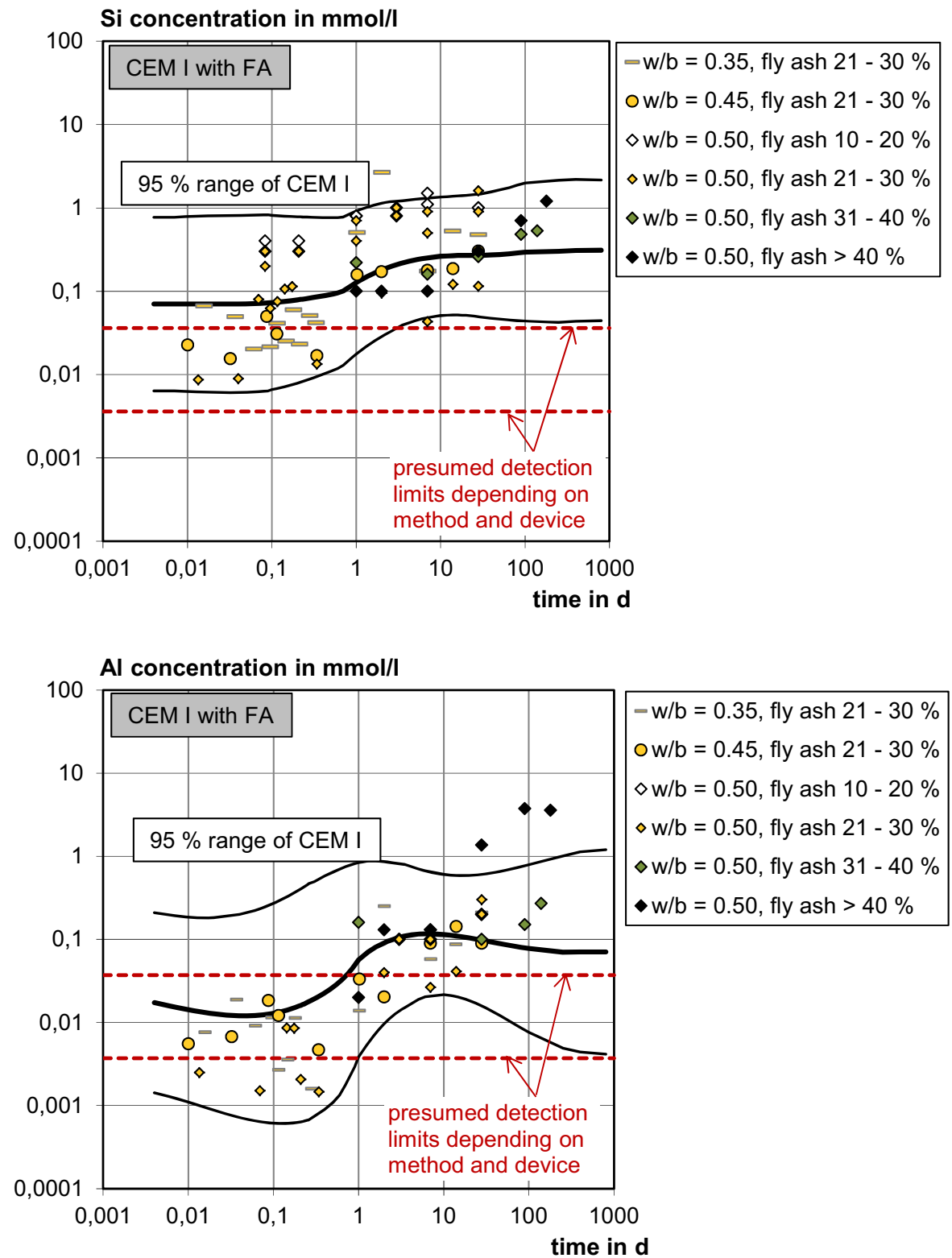

As for FA, the calculations predict a decrease of calcium and an increase of silicon, aluminium and sulfate concentrations, which is however not well visible in the very few experimental data.

The modelled trends show a good agreement with the available experimental data from literature, especially considering the differences in materials and experimental methods. As mentioned before, the decrease in solution alkalinity with increasing SCM blending is well reproduced illustrating that alkali uptake into the $\mathrm{C}-\mathrm{S}-\mathrm{H}$ is at least qualitatively captured by the model. Apparently, Na concentrations are underestimated which is most likely due to systematically low reported $\mathrm{Na}_{2} \mathrm{O}$ levels in the raw materials and not to a deficiency in the model. The total content of $\mathrm{Na}_{2} \mathrm{O}$ is often determined with XRF and sodium tends to evaporate when preparing fused tablets for XRF [85]. In addition, considering the 

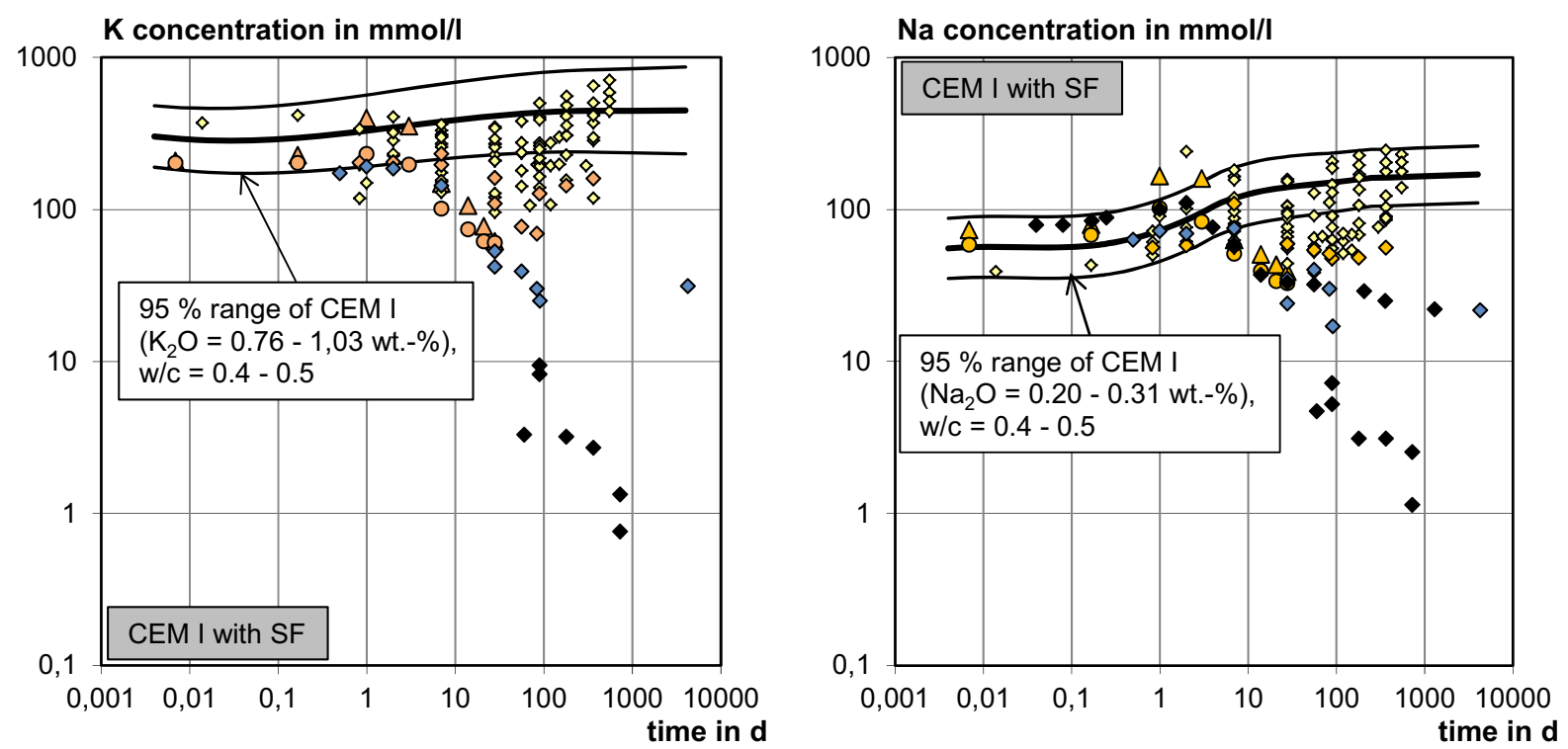

$\mathrm{OH}^{-}$concentration in $\mathrm{mmol} / \mathrm{l}$

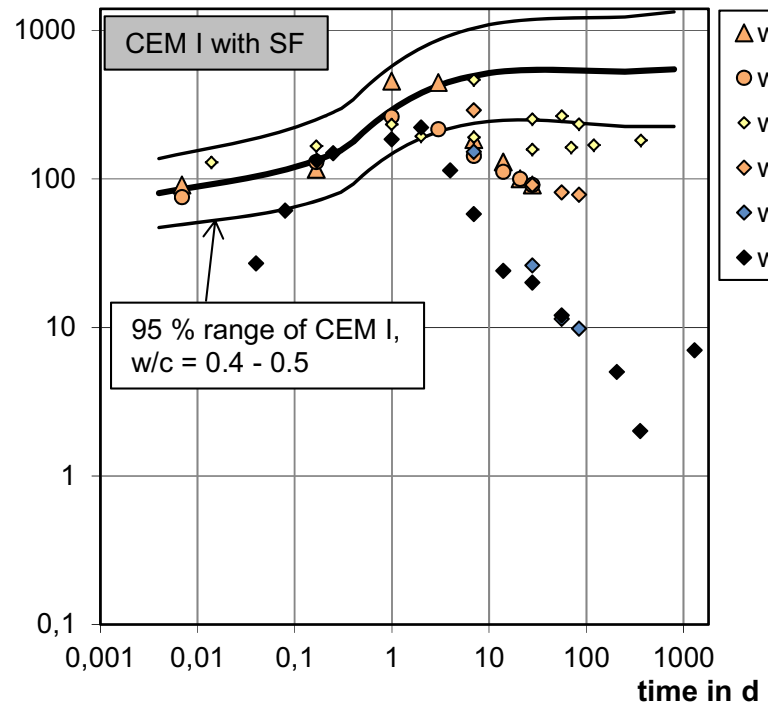

Fig. 21 Potassium, sodium and hydroxide concentrations in the pore solution of SF blended cement pastes compared to the $95 \%$ range of CEM I, calculated in Sect. 3.1.2 [2, 5, 7, 8, 13, 15, 16, 25, 28, 29, 31, 33, 40, 41]

scatter in Ca levels for the $0 \%$ SF data, the model represents well the experimentally determined $\mathrm{Ca}$ concentrations. Also for $\mathrm{Al}, \mathrm{Si}$ and sulfate the experimental data remain within one order of magnitude of the modelled concentration. However, as experimental data on $\mathrm{Al}, \mathrm{Si}$ and sulfate are relatively scarce, it is not clear whether the observed remaining discrepancies are related to experimental scatter or to a shortcoming of the thermodynamic model used.

\section{Summary and outlook}

This paper reviews and evaluates the impact of GGBS, FA and SF on the cement pore solution composition. Practical guidelines are given for the extraction and the chemical analysis of the cement pore solution. Reported experimental data on pore solution composition are collected in a database and variations in composition over time and between systems are statistically evaluated and described. The observed 
Fig. 22 Calcium and sulfate concentrations in the pore solution of SF blended cement pastes compared to the $95 \%$ range of CEM I, calculated according to Sect. 3.1.1 [1, 2, 5, 7, 8, 13, $15,25,28,29,33,41]$

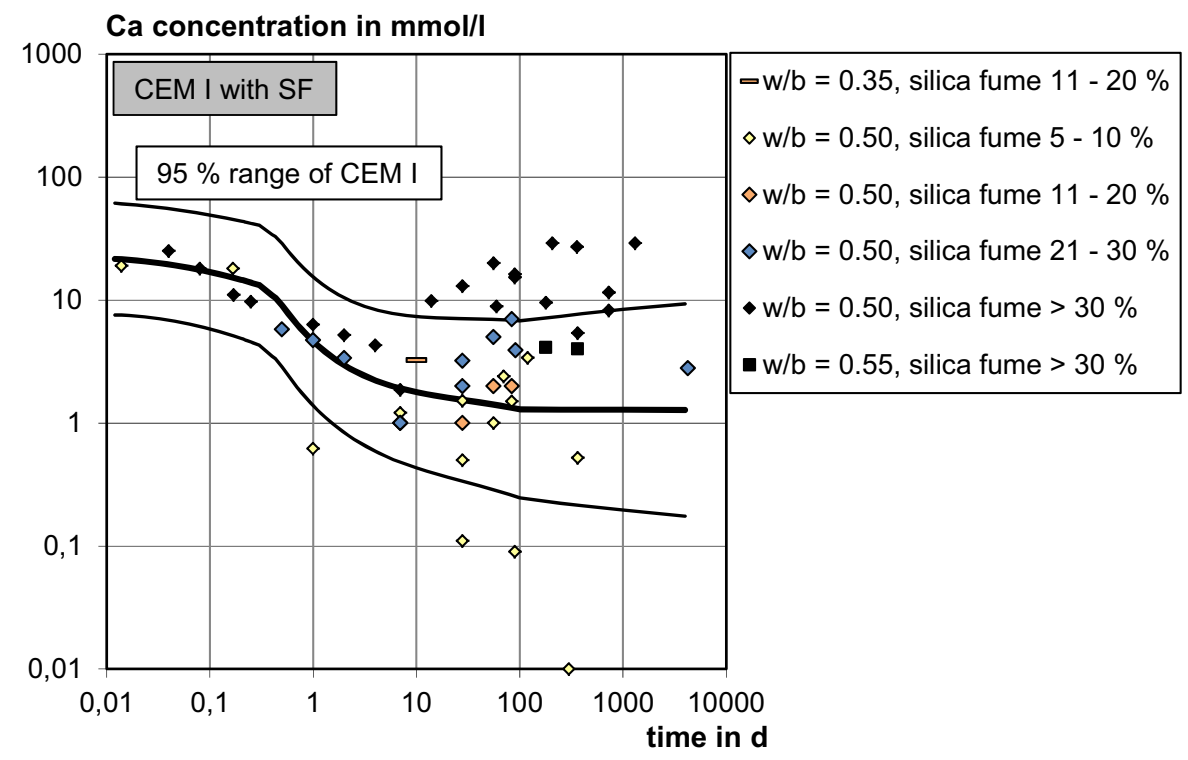

sulfate concentration in $\mathrm{mmol} / \mathrm{l}$

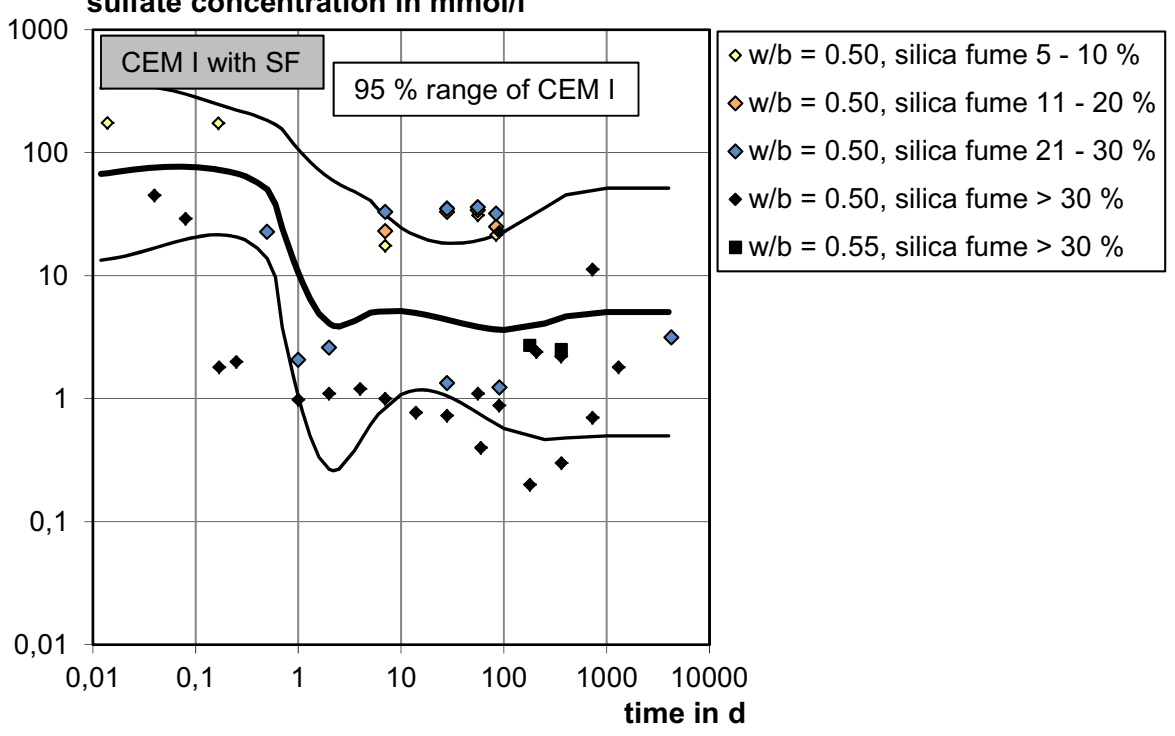

trends are compared to calculations of a state-of-theart thermodynamic model for cements blended with increasing amounts of FA and SF.

The reviewed experimental data show considerable scatter because of the use of different PCs, SCMs, water to cement ratios and analytical methods. Nevertheless, following common trends are observed concerning the impact of SCMs on the cement pore solution:
- Alkali concentrations generally decrease with increasing replacement of PC by SCMs. Alkali concentrations in the pore solution depend strongly on the total alkali content of the PC. Partial replacement by SCMs thus reduces alkali concentrations as the alkalis incorporated in the glass fraction of the SCMs are released more slowly than the alkalis from the cement. In addition, the pozzolanic reaction of the SCMs leads to the 
Fig. 23 Calcium concentrations in pore solutions of all types of binders considered in this paper at later ages ( $\geq 7$ days) depending on $\mathrm{pH}$-value compared to calcium concentrations in leachates of crushed CEM I mortars $(<4 \mathrm{~mm})$ at fixed $\mathrm{pH}$-values, reproduced from [84] and solubility data for portlandite, *outlier

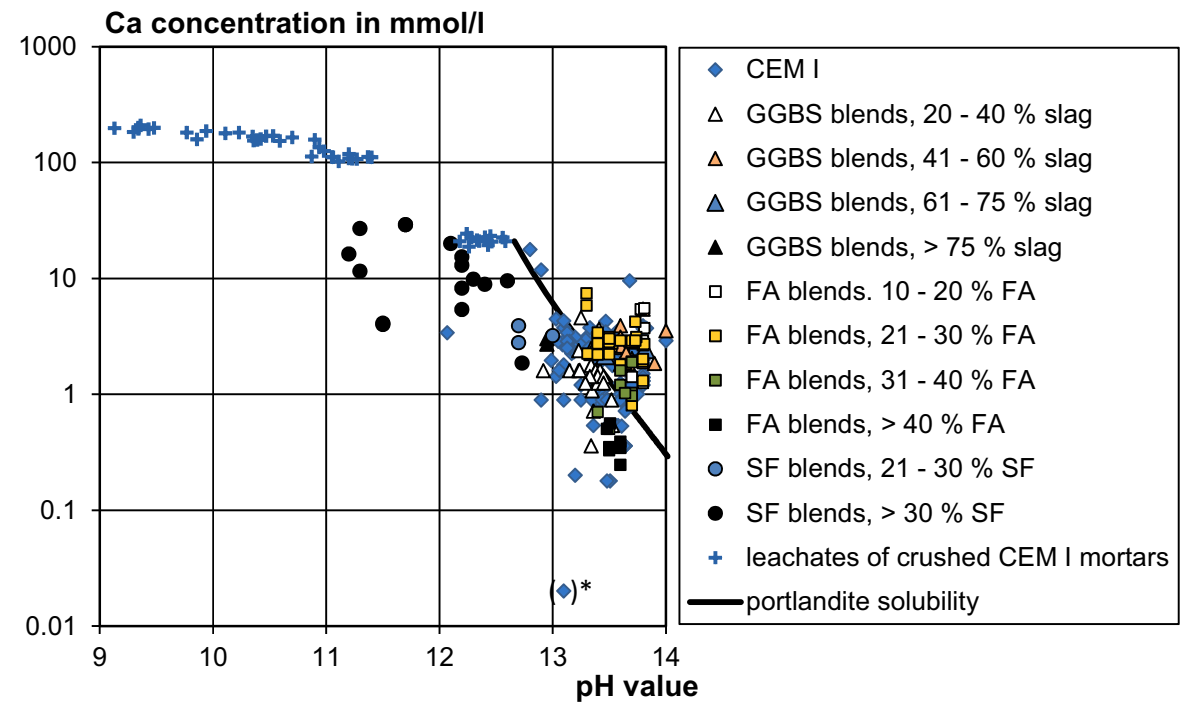

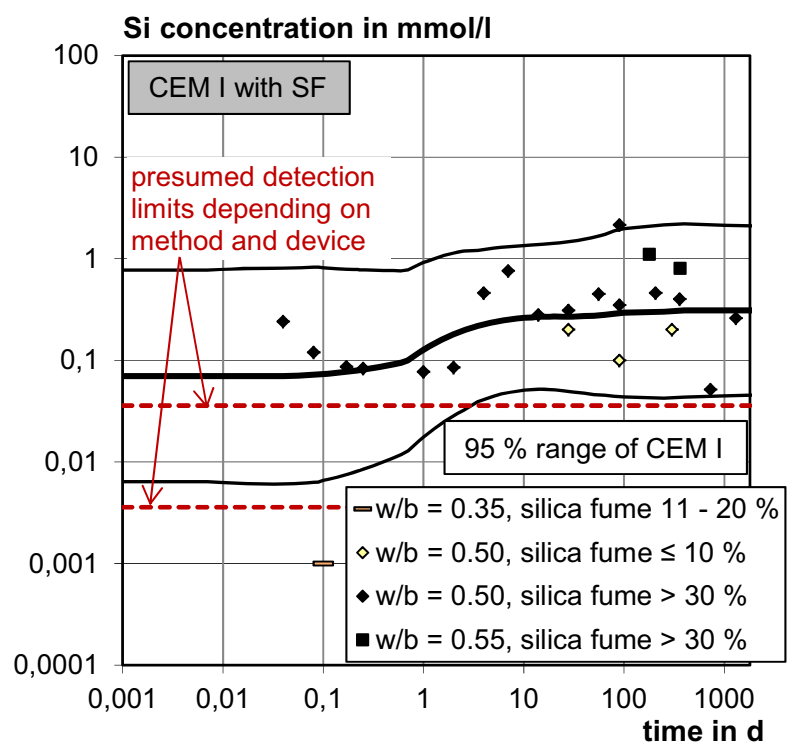

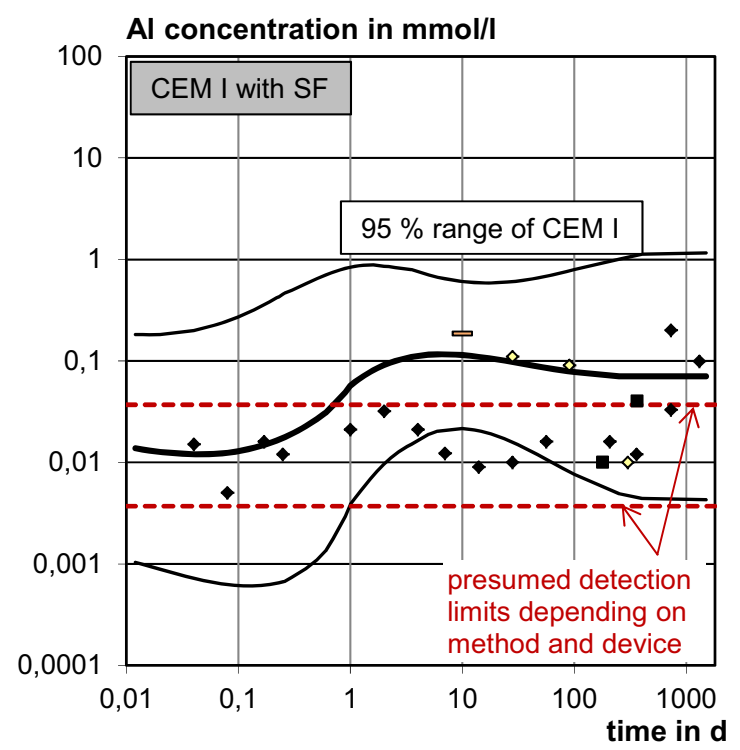

Fig. 24 Silicon and aluminium concentrations in the pore solution of SF blended cement pastes compared to the $95 \%$ range of CEM I, calculated in Sect. 3.1.4 [2, 7, 13, 25, 29, 41]

formation of more $\mathrm{C}-\mathrm{S}-\mathrm{H}$ of lower $\mathrm{Ca} / \mathrm{Si}$ ratio which in turn results in an increased alkali binding since low $\mathrm{Ca} / \mathrm{Si} \mathrm{C}-\mathrm{S}-\mathrm{H}$-phases take up more alkalis $[78,83]$. SF is most effective in reducing the alkali concentration of the pore solution.

In the thermodynamic model, the use of an ideal solid solution model between $\mathrm{C}-\mathrm{S}-\mathrm{H}$ and two hypothetical alkali silicate hydrates [24] enables to reproduce well the decrease of alkali concentrations in the pore solution of FA and SF cements.

- The decreased alkali concentrations in the pore solution lead to reduced $\mathrm{OH}^{-}$concentrations. In the case of GGBS negatively charged sulfur species such as sulfide or thiosulfate can additionally decrease the $\mathrm{OH}^{-}$concentrations of the pore solution. The trends in the experimental data are in 


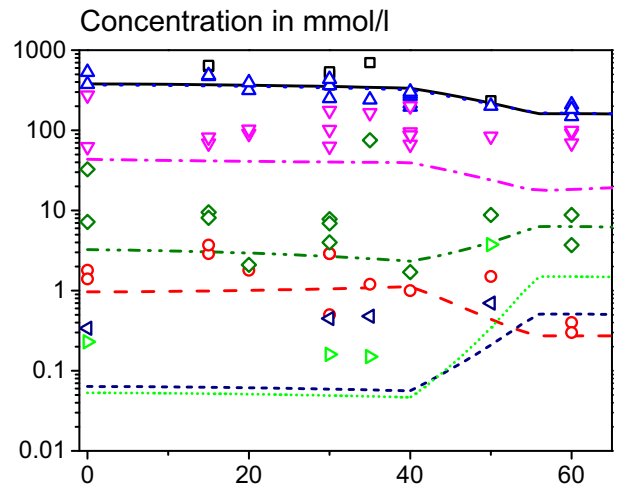

Fly ash content in \%

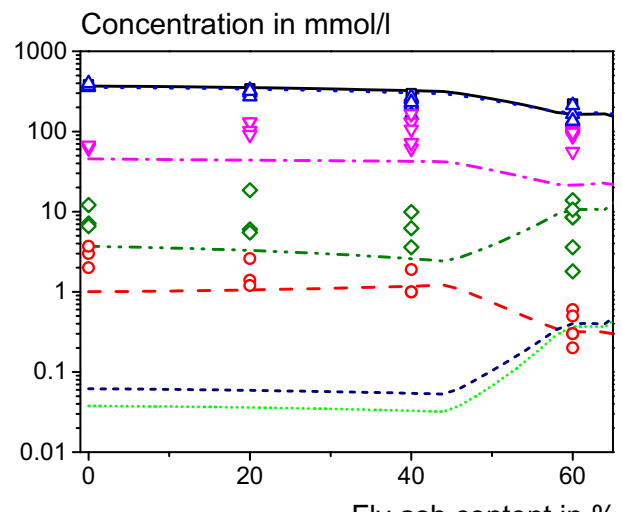

Fly ash content in \%

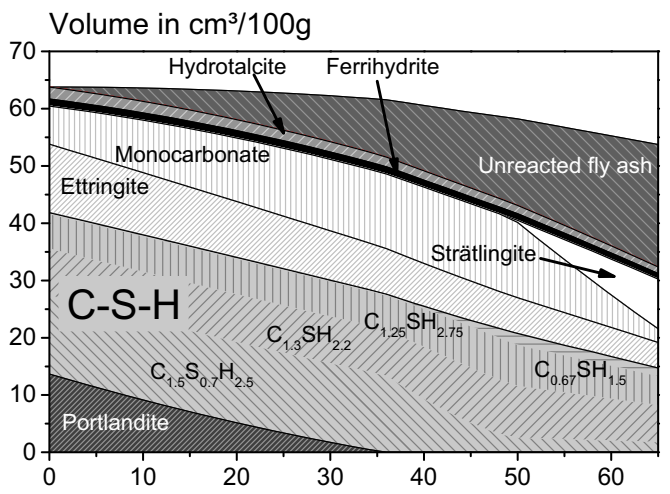

Fly ash content in \%

Fig. 25 Comparison between collected experimental pore solution data (points [3, 5, 10, 31, 39]) and modelled pore solution compositions (lines): top 28 days of hydration, middle 12 years and solid phase assemblage (bottom 12 years) as a function of the fly ash fraction in the blended cement

line with modelled $\mathrm{OH}^{-}$concentrations for $\mathrm{FA}$ and SF blended cements.

- Sulfate concentrations are not significantly affected by GGBS or FA blending. Calcium concentrations tend to decrease at high FA and
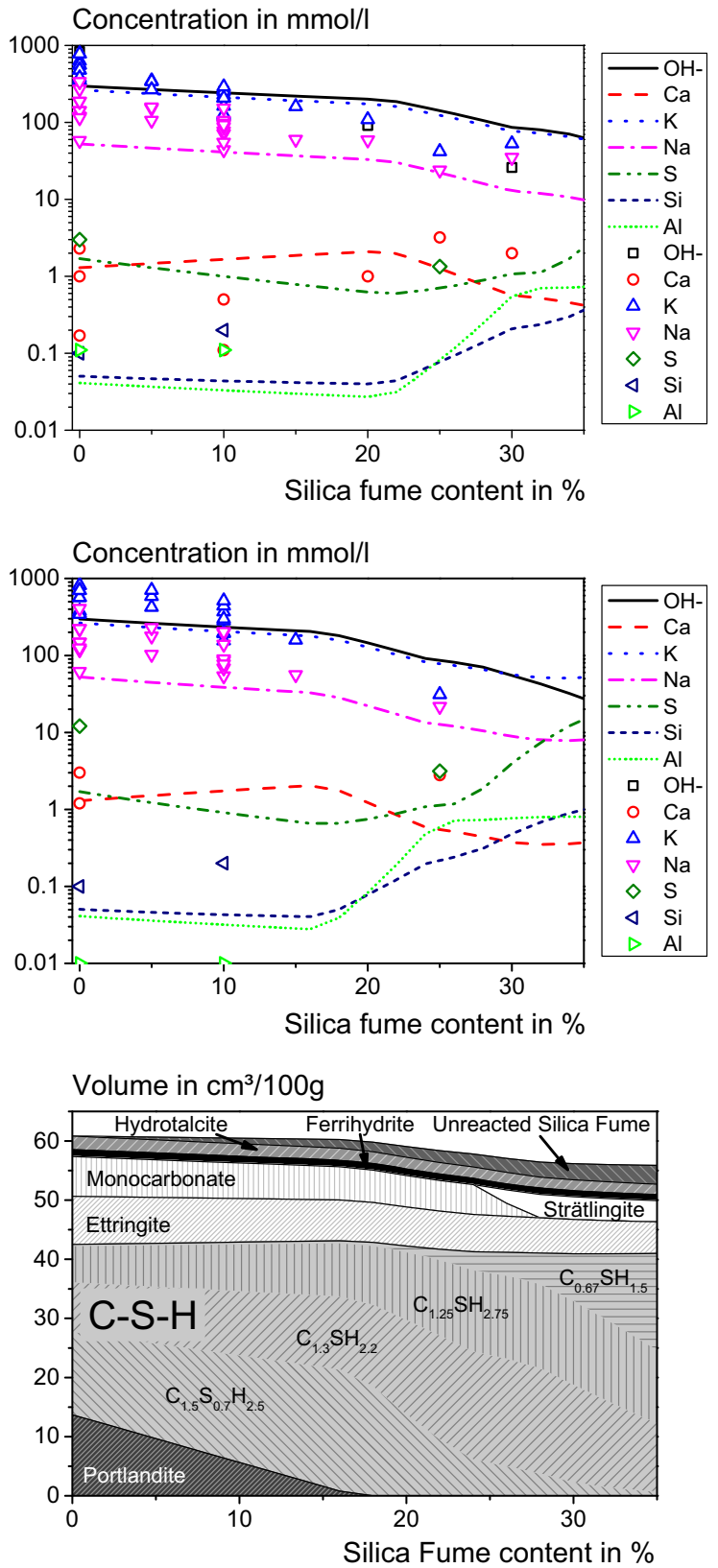

Fig. 26 Comparison between collected experimental pore solution data (points $[5,7,25,28,31,40,41])$ and modelled pore solution compositions (lines): top 28 days of hydration, middle $\geq 150$ days and solid phase assemblage (bottom $\geq 150$ days) as a function of the silica fume fraction in the blended cement

GGBS replacement levels ( $>60 \mathrm{wt} \%$ ). The latter trend is neatly reproduced by the thermodynamic model that calculates a decrease of calcium 
concentrations only when portlandite is (being) depleted.

In contrast, blends with SF deviate from the thermodynamic model at high replacement ratios (>30 wt\%) and low pore solution pH. Contradictory to the modelling results the experimental data indicate an increase of calcium and a decrease in sulfate concentrations.

- Reported measured silicon and aluminium concentrations are few. Because of the low concentrations the scatter on the chemical analysis results is high and changes that might occur are difficult to detect. Therefore some of the very low measurements given in literature may not be reliable. The available data do not show changes in the silicon and aluminium concentrations of GGBS and SF blends compared to pure PC pastes, whilst for FA blends the aluminium concentration tends to increase over time and with an increasing replacement ratio. The latter observation is reproduced by thermodynamic modelling that predicts rising aluminium (and silicon) concentrations beyond portlandite depletion.

In general the comparison between experimental and modelled trends shows a good agreement, especially considering the differences in materials and experimental methods. Some discrepancies, such as noted for $\mathrm{Ca}$ and $\mathrm{Si}$ concentrations in low $\mathrm{pH}$, high SF cements, indicate that the currently used $\mathrm{C}-\mathrm{S}-\mathrm{H}$ model can be improved further for non-standard conditions and mixes. In addition, not only potassium and sodium, but also many other ions including aluminium, iron, chloride, sulfate or carbonate can be taken up by the $\mathrm{C}-\mathrm{S}-\mathrm{H}$ phase, which was not considered in the present model. Low $\mathrm{C}-\mathrm{S}-\mathrm{H} \mathrm{Ca} / \mathrm{Si}$ ratios, as present in blended or alkali activated slag or FA systems, increase the uptake of $\mathrm{Al}$ in $\mathrm{C}-\mathrm{S}-\mathrm{H}$ [86] and decrease the uptake of sulfate [87]. More systematic experimental data on the uptake by $\mathrm{C}-\mathrm{S}-\mathrm{H}$ of other cations and anions as well as on their reciprocal influence are therefore welcomed to further improve our knowledge and predictions of the fate of these ions in hydrated cements.

The effect of elevated temperature is also an important topic, especially for massive concrete structures. At the moment, only a few studies concerning this topic exist (e.g., [2, 10, 29]).

\section{References}

1. Andersson K, Allard B, Bengtsson M, Magnusson B (1989) Chemical composition of cement pore solutions. Cem Concr Res 19(3):327-332

2. Bach TTH, Cau-dit-Coumes C, Pochard I, Mercier C, Revel B, Nonat A (2012) Influence of temperature on the hydration products of low $\mathrm{pH}$ cements. Cem Concr Res 42(6):805-817. doi:10.1016/j.cemconres.2012.03.009

3. Berry EE, Hemmings RT, Langley WS, Carette GG (1989) Beneficiated fly ash: hydration, microstructure, and strength development in Portland cement systems. In: Malhotra VM (ed) Fly ash, silica fume, slag, and natural pozzolans in concrete, ACI SP-114. American Concrete Institute, Detroit, pp 241-273

4. Bérubé MA, Tremblay C, Fournier B, Thomas MD, Stokes DB (2004) Influence of lithium-based products proposed for counteracting ASR on the chemistry of pore solution and cement hydrates. Cem Concr Res 34(9):1645-1660

5. Brameshuber W, Vollpracht A (2007) Strukturuntersuchungen an 10 Jahre alten Zementsteinproben. Report No. F 928. Institute of Building Materials Research, RWTH Aachen University (unpublished)

6. Brendle S, de Rooij MR, van Breugel K (2008) Pore solution evolution during the early Portland cement hydration. Restor Build Monum 14(2):141-152

7. Chappex T (2012) The role of aluminium from supplementary cementitious materials in controlling alkali-silica reaction. Dissertation, École polytechnique fédérale de Lausanne

8. Codina M, Cau-dit-Coumes C, Le Bescop P, Verdier J, Ollivier JP (2008) Design and characterization of low heat and low-alkalinity cements. Cem Concr Res 38(4):437-448. doi:10.1016/j.cemconres.2007.12.002

9. Diamond S (1981) Effects of two Danish fly ashes on alkali contents of pore solutions of cement-fly ash pastes. Cem Concr Res 11(3):383-394

10. Deschner F, Lothenbach B, Winnefeld F (2013) Effect of temperature on the hydration Portland cement blended with siliceous fly ash. Cem Concr Res 52:169-181. doi:10.1016/ j.cemconres.2013.07.006

11. Fraay ALA (1990) Fly ash a pozzolan in concrete. Dissertation, Technical University, Delft

12. Fujii K, Kondo W, Watanabe T (1970) Über die Hydratation von Portlandzement sofort nach dem Anmachen. Zement Kalk Gips 23(2):72-79

13. Garcia Calvo JL, Hidalgo A, Alonso C, Fernandez Luco L (2010) Development of low-pH cementitious materials for HLRW repositories. Resistance against ground waters aggression. Cem Concr Res 40(8):1290-1297. doi:10.1016/ j.cemconres.2009.11.008

14. Gartner EM, Tang FJ, Weiss SJ (1985) Saturation factors for calcium hydroxide and calcium sulfates in fresh Portland cement pastes. J Am Ceram Soc 68(12):667-673. doi:10. 1111/j.1151-2916.1985.tb10122.x

15. Hüttl R (2000) Der Wirkungsmechanismus von Steinkohlenflugasche als Betonzusatzstoff. Dissertation, Technical University, Berlin

16. Larbi JA, Fraay ALA, Bijen JMJM (1990) The chemistry of the pore fluid of silica fume-blended cement systems. Cem Concr Res 20(4):506-516 
17. Le Saoût G, Lothenbach B, Hori A, Higuchi T, Winnefeld F (2013) Hydration of Portland cement with additions of calcium sulfoaluminates. Cem Concr Res 43:81-94. doi:10. 1016/j.cemconres.2012.10.011

18. Longuet P, Burglen L, Zelwer A (1973) La phase liquide du ciment hydrate. Rev matér constr 676:35-41

19. Lorenzo P, Goñi S, Hernandez S, Guerrero A (1996) Effect of fly ashes with high alkali content on the alkalinity of the pore solution of hydrated Portland cement paste. J Am Ceram Soc 79(2):470-474. doi:10.1111/j.1151-2916.1996. tb08146.x

20. Lothenbach B, Wieland E (2006) A thermodynamic approach to the hydration of sulphate-resisting Portland cement. Waste Manag 26(7):706-719. doi:10.1016/j. wasman.2006.01.023

21. Lothenbach B, Winnefeld F (2006) Thermodynamic modelling of the hydration of Portland cement. Cem Concr Res 36(2):209-226. doi:10.1016/j.cemconres.2005.03.001

22. Lothenbach B, Winnefeld F, Alder C, Wieland E, Lunk P (2007) Effects of temperature on the pore solution, microstructure and hydration products of Portland cement pastes. Cem Concr Res 37(4):483-491. doi:10.1016/j. cemconres.2006.11.016

23. Lothenbach B, Le Saout G, Gallucci E, Scrivener K (2008) Influence of limestone on the hydration of Portland cements. Cem Concr Res 38(6):848-860. doi:10.1016/j.cemconres. 2008.01.002

24. Lothenbach B, Le Saoût G, Ben Haha M, Figi R, Wieland E (2012) Hydration of a low-alkali CEM III/B-SiO ${ }_{2}$ cement (LAC). Cem Concr Res 42(2):410-423. doi:10.1016/j. cemconres.2011.11.008

25. Lothenbach B, Rentsch D, Wieland E (2014) Hydration of a silica fume blended low-alkali shotcrete cement. J Phys Chem Earth 70-71:3-16. doi:10.1016/j.pce.2013.09.007

26. Luke K, Glasser FP (1986) Chemical changes occurring during the early hydration of PFA-OPC mixtures. MRS Proc 65:173-180. doi:10.1557/PROC-65-173

27. Nixon PJ, Page CL, Bollinghaus R, Canham I (1986) The effect of a PFA with a high total alkali content on pore solution composition and alkali silica reaction. Mag Concr Res 38(134):30-35

28. Page CL, Vennesland O (1982) Pore solution composition and chloride binding capacity of silica fume-cement pastes. Report Number STF65 A82025. Norwegian Institute of Technology, Cement and Concrete Research Institute, FCB, Trondheim

29. Ramlochan T, Zacarias P, Thomas MDA, Hooton RD (2004) The effect of pozzolans and slag on the expansion of mortars cured at elevated temperature. Part II: microstructural and microchemical investigations. Cem Concr Res 34(8):1341-1356

30. Rothstein D, Thomas JJ, Christensen BJ, Jennings HM (2002) Solubility behaviour of Ca-, S-, Al-, and Si-bearing solid phases in Portland cement pore solutions as a function of hydration time. Cem Concr Res 32(10):1663-1671. doi:10.1016/S0008-8846(02)00855-4

31. Schäfer E (2005) Einfluss der Reaktionen verschiedener Zementhauptbestandteile auf den Alkalihaushalt der Porenlösung des Zementsteins. Schriftenreihe der Zementindustrie (69). Dissertation, Technical University, Clausthal
32. Schieß1 P, Härdtl R, Moersch J (1995) Untersuchungen zur Verwendung von Steinkohlenflugasche in Spannbeton mit sofortigem Verbund. Report No. F 430. Institute of Building Materials Research, RWTH Aachen University

33. Schieß1 P, Meng B (1996) Grenzen der Anwendbarkeit von Puzzolanen im Beton. Report No. F 405. Institute of Building Materials Research, RWTH Aachen University

34. Schieß1 P, Moersch J, Schröder P (1997) Verwendung von Hochofenzement (CEM III) in Spannbeton mit sofortigem Verbund. Report No. F 566. Institute of Building Materials Research, RWTH Aachen University

35. Silsbee M, Malek RIA, Roy DM (1986) Composition of pore fluids extruded from slag-cement pastes. In: International congress on the chemistry of cement, Rio de Janeiro, pp 263-269

36. Stassinopoulos EN (1982) Untersuchung über die Zusammensetzung der flüssigen Phase und die Migrations-Prozesse in Zementpasten und Mörteln. Dissertation, Technical University, Clausthal

37. Thomas JJ, Rothstein D, Jennings HM, Christensen BJ (2003) Effect of hydration temperature on the solubility behavior of Ca-, S-, Al-, and Si-bearing solid phases in Portland cement pastes. Cem Concr Res 33(12):2037-2047. doi:10.1016/S0008-8846(03)00224-2

38. Vollpracht A (2012) Einbindung von Schwermetallen in Portlandzementstein. Schriftenreihe Aachener Beiträge zur Bauforschung (18). Dissertation, RWTH Aachen University. ISBN 3-86130-635-2

39. de Weerdt K, Ben Haha M, Le Saout G, Kjellsen KO, Justnes H, Lothenbach B (2011) Hydration mechanisms of ternary Portland cements containing limestone powder and fly ash. Cem Concr Res 41(3):279-291. doi:10.1016/j. cemconres.2010.11.014

40. Duchesne J (2013) Alkali concentrations in pore solutions of pastes made of Portland cement with and without supplementary cementitious materials. Département de géologie et de génie géologique, Université Laval, Québec (unpublished)

41. Lothenbach B (2013) Pore solution of cement pastes with high amounts of silica fume at different temperatures. Empa Material Science and Technology (unpublished)

42. Vollpracht A (2013) Pore solution of cement pastes with Portland cement with and without fly ash and blast furnace slag cement. Institute of Building Materials Research, RWTH Aachen University (unpublished)

43. Boddy AM, Hooton RD, Thomas MDA (2003) The effect of the silica content of silica fume on its ability to control alkali-silica reaction. Cem Concr Res 33(8):1263-1268

44. van Eijk RJ, Brouwers HJH (2000) Prediction of hydroxyl concentrations in cement pore water using a numerical cement hydration model. Cem Concr Res 30(11): 1801-1806

45. Canham I, Page CL, Nixon PJ (1987) Aspects of the pore solution chemistry of blended cements related to the control of alkali silica reaction. Cem Concr Res 17(5): 839-844

46. Kawamura M, Takemoto K (1986) Effects of pozzolans and a blast furnace slag on alkali hydroxides concentrations in pore solutions and alkali-silica expansion. In: Review of the 40th general meeting, technical session, 1986. Cement Association of Japan, Tokyo, pp 262-265 
47. Hooton RD, Thomas MDA, Ramlochan T (2010) Use of pore solution analysis in design for concrete durability. Adv Cem Res 22(4):203-210. doi:10.1680/adcr.2010.22.4.20

48. Goldschmidt A (1982) About the hydration theory and the composition of the liquid phase of Portland cement. Cem Concr Res 12(6):743-746

49. Michaux M, Fletcher P, Vidick B (1989) Evolution at early hydration times of the chemical composition of liquid phase of oil-well cement pastes with and without additives. Part I. Additive free cement pastes. Cem Concr Res 19(3):443-456

50. Locher FW, Richartz W, Sprung S (1976) Erstarren von Zement I: Reaktion und Gefügeentwicklung. Zement Kalk Gips 29(10):435-442

51. Locher FW, Richartz W, Sprung S, Rechenberg W (1983) Erstarren von Zement IV: Einfluss der Lösungszusammensetzung. Zement Kalk Gips 36(4):224-231

52. Vernet C, Démoulian E, Gourdin P, Hawthorn F (1980) Hydration kinetics of Portland cement. In: 7th International congress on the chemistry of cement, Paris, pp 219-224

53. Vernet C, Démoulian E, Gourdin P, Hawthorn F (1980) Kinetics of slag cements hydration. In: 7th International congress on the chemistry of cement, Paris, pp 128-133

54. Way SJ, Shayan A (1989) Early hydration of a Portland cement in water and sodium hydroxide solutions: composition of solutions and nature of solid phases. Cem Concr Res 19(5):759-769

55. Chatterji S (1991) On the relevance of expressed liquid analysis to the chemical processes occurring in cement paste. Cem Concr Res 21(2-3):269-272

56. Lothenbach B (2010) Thermodynamic equilibrium calculations in cementitious systems. Mater Struct 43(10):14131433. doi:10.1617/s11527-010-9592-x

57. Duchesne J, Bérubé MA (1994) The effectiveness of supplementary cementing materials in suppressing expansion due to ASR: another look at the reaction mechanisms. Part 2: pore solution chemistry. Cem Concr Res 24(2):221-230

58. Duchesne J, Bérubé MA (1994) Evaluation of the validity of the pore solution expression method from hardened cement pastes and mortars. Cem Concr Res 24(3):456-462

59. Tritthart J (1989) Chloride binding in cement-I. Investigations to determine the composition of pore water in hardened cement. Cem Concr Res 19(4):586-594

60. Bérubé MA, Tremblay C (2004) Chemistry of pore solution expressed under high pressure-influence of various parameters and comparison with the hot-water extraction method. In: 12th International conference on alkali-aggregate reaction in concrete, Beijing, pp 833-842

61. Leemann A, Loertscher L, Bernard L, Le Saout G, Lothenbach B, Espinosa-Marzal R (2014) Mitigation of ASR by the use of $\mathrm{LiNO}_{3}$ - characterization of the reaction products. Cem Concr Res 59:73-86. doi:10.1016/j.cem conres.2014.02.003

62. Wagner T, Kulik DA, Hingerl FF, Dmytrieva SV (2012) GEM-Selektor geochemical modeling package: TSolMod library and data interface for multicomponent phase models. Can Miner 50:1173-1195. doi:10.3749/canmin.50.5.1173

63. Kulik D, Wagner T, Dmytrieva SV, Kosakowski G, Hingerl F, Chudnenko KV, Berner U (2013) GEM-Selektor geochemical modeling package: revised algorithm and GEMS3K numerical kernel for coupled simulation codes. Comput Geochem 17(1):1-24. doi:10.1007/s10596-012-9310-6
64. Hummel W, Berner U, Curti E, Pearson FJ, Thoenen T (2002) Nagra/PSI chemical thermodynamic data base 01/01. Radiochim Acta 90(9-11):805-813. doi:10.1524/ ract.2002.90.9-11_2002.805

65. Thoenen T (2012) The PSI/Nagra chemical thermodynamic database 12/07: compilation of updated and new data with respect to the Nagra/PSI chemical thermodynamic data base 01/01. PSI Internal Report, TM-44-12-06. Paul Scherrer Institut, Villigen

66. Matschei T, Skapa R, Lothenbach B, Glasser FP (2007) The distribution of sulfate in hydrated Portland cement paste. In: 12th International congress on the chemistry of cement, Montreal, Canada

67. Lothenbach B, Matschei T, Möschner G, Glasser FP (2008) Thermodynamic modelling of the effect of temperature on the hydration and porosity of Portland cement. Cem Concr Res 38(1):1-18. doi:10.1016/j.cemconres.2007.08.017

68. Dilnesa BZ, Lothenbach B, Renaudin G, Wichser A, Kulik D (2014) Synthesis and characterization of hydrogarnet $\mathrm{Ca}_{3}\left(\mathrm{Al}_{\mathrm{x}} \mathrm{Fe}_{1}-\mathrm{x}\right)_{2}\left(\mathrm{SiO}_{4}\right)_{\mathrm{y}}(\mathrm{OH})_{4(3-\mathrm{y})}$. Cem Concr Res 59:96-111. doi:10.1016/j.cemconres.2014.02.001

69. Kulik DA (2011) Improving the structural consistency of C$\mathrm{S}-\mathrm{H}$ solid solution thermodynamic models. Cem Concr Res 41(5):477-495. doi:10.1016/j.cemconres.2011.01.012

70. Schmidt T, Lothenbach B, Romer M, Scrivener KL, Rentsch D, Figi R (2008) A thermodynamic and experimental study of the conditions of thaumasite formation. Cem Concr Res 38(3):337-349. doi:10.1016/j.cemconres.2007.11.003

71. Kulik D, Tits J, Wieland E (2007) Aqueous-solid solution model of strontium uptake in $\mathrm{C}-\mathrm{S}-\mathrm{H}$ phases. Geochim Cosmochim Acta 71(12, Supplement 1):A530

72. Lothenbach B, Scrivener K, Hooton RD (2011) Supplementary cementitious materials. Cem Concr Res 41(3):217-229. doi:10.1016/j.cemconres.2010.12.001

73. Baert G (2009) Physico-chemical interactions in Portland cement-(high volume) fly ash binders. Dissertation, Ghent University

74. Vollpracht A, Brameshuber W (2010) Investigations on ten years old hardened cement paste samples. In: Proceedings of the international RILEM conference on materials science (MatSci), Vol. III: additions improving properties of concrete (AdIPoC). RILEM, Bagneux, pp 79-91

75. Poulsen SL, Jakobsen HJ, Skibsted J (2009) Methodologies for measuring the degree of reaction in Portland cement blends with supplementary cementitious materials by ${ }^{27} \mathrm{Al}$ and ${ }^{29} \mathrm{Si}$ MAS NMR spectroscopy. In: 17 Internationale Baustofftagung (ibausil), Weimar, Germany

76. Skibsted J, Jensen OM, Jakobsen HJ (1997) Hydration kinetics for the alite, belite, and calcium aluminate phase in Portland cements from ${ }^{27} \mathrm{Al}$ and ${ }^{29} \mathrm{Si}$ MAS NMR spectroscopy. In: Justness H (ed) 10th international congress on the chemistry of cement, Göteborg, p 2 ii056

77. Pietersen HS, Kentgens APM, Nachtegaal GH, Veeman WS, Bijen JM (1992) The reaction mechanism of blended cements: a ${ }^{29}$ Si NMR study. In: Malhotra VM (ed) 4th international conference on fly ash, silica fume, slag and natural pozzolans in concrete. CANET/ACI SP 132-47, Istanbul, Turkey, pp 795-812

78. Hong S-Y, Glasser FP (1999) Alkali binding in cement pastes. Part I. The C-S-H phase. Cem Concr Res 29(12):1893-1903. doi:10.1016/S0008-8846(99)00187-8 
79. Moragues A, Macias A, Andrade C (1987) Equilibria of the chemical composition of the concrete pore solution. Part 1: comparative study of synthetic and extracted solutions. Cem Concr Res 17(2):173-182

80. Diamond S, Ong S (1994) Effects of added alkali hydroxides in mix water on long-term $\mathrm{SO}_{4}{ }^{2-}$ concentrations in pore solution. Cem Concr Compos 16(3):219-226

81. Goñi S, Lorenzo MP, Guerrero A, Hernández MS (1996) Calcium hydroxide saturation factors in the pore solution of hydrated Portland cement fly ash pastes. J Am Ceram Soc 79(4):1041-1046. doi:10.1111/j.1151-2916.1996.tb08545.x

82. Stark J, Möser B, Bellmann F (2007) Quantitative characterization of cement hydration. In: 5th International Essen workshop, transport in concrete: nano- to macrostructure, Essen, Germany. Aedification Publishers, Freiburg

83. Stade H (1989) On the reaction of C-S-H(di, poly) with alkali hydroxides. Cem Concr Res 19(5):802-810
84. van der Sloot HA, Hoede D, Rietra RPJJ et al (2001) Environmental criteria for cement based products: ECRICEM. Phase I: ordinary Portland cements. Report No. ECNC-01-069. Energy Research Centre of the Netherlands, Petten

85. Buhrke V, Jenkins R, Smith D (1998) A practical guide for the preparation of specimens for X-ray fluorescence and $\mathrm{X}$-ray diffraction analysis. Wiley-VCH, New York

86. Faucon P, Delagrave A, Petit JC, Richet C, Marchand J, Zanni H (1999) Aluminium incorporation in calcium silicate hydrates $(\mathrm{C}-\mathrm{S}-\mathrm{H})$ depending on their $\mathrm{Ca} / \mathrm{Si}$ ratio. J Phys Chem B 103:7796-7802. doi:10.1021/jp990609q

87. Matschei T, Lothenbach B, Glasser FP (2007) Thermodynamic properties of Portland cement hydrates in the system $\mathrm{CaO}-\mathrm{Al}_{2} \mathrm{O}_{3}-\mathrm{SiO}_{2}-\mathrm{CaSO}_{4}-\mathrm{CaCO}_{3}-\mathrm{H}_{2} \mathrm{O}$. Cem Concr Res 37(10):1379-1410. doi:10.1016/j.cemconres.2007.06.002 